\title{
XXXVII. Die Praxis in der krystallochemischen Analyse und die Abfassung der Tabellen für dieselbe.
}

\author{
Von \\ E. von Fedorow in St. Petersburg.
}

(Hierzu Tafel XI.)

Die jetzige menschliche und ganz besonders die europäisch-amerikanische Cultur ist mit den Fortschritten einer Reihe besonderer Wissenschaften so eng verknüpft, daß man hätte sagen können, sie erhalte dadurch einen besonderen Stempel aufgedrückt, und sie unterscheidet sich in dieser Hinsicht scharf von allen früheren Culturen.

Der Grund dieser Sachlage ist, daß die so enorm entwickelten Wissenschaften nicht allein den geistigen Anforderungen eines Teiles der Menschheit entgegenkommen, sondern zugleich ihr die große Macht zuerteilen, die in der Natur wirkenden Kräfte und Erscheinungen zugunsten der Menschen überhaupt zu richten und somit die Natur selbst in stets höherem Grade der Menschheit dienstbar zu machen.

In dem Gange der letzten Periode der Culturgeschichte prägt sich von selbst die Aufgabe und der Beruf der besonderen Wissenschaften aus, in der oder jener Hinsicht die Natur zu bewältigen und in gewissem Gebiet der Naturerscheinungen dieselben entsprechend dem Wunsche der Menschen zu richten.

Nun sind aber durchaus nicht alle Naturwissenschaften in gleiche Reihe zu stellen.

Das kurze Eindringen in die Sachlage macht uns klar, daß in dieser Beziehung der erste Platz unbestreitbar den physikalisch-chemischen Disciplinen zukommt, zugleich auch den mathematischen, als solchen, welche die Grundlage dieser Disciplinenreihe bilden und zu Hauptleiterinnen in dem fortschreitenden Gange derselben dienen.

Aber sogar in dieser begrenzten und hervorragenden Disciplinenreihe sind durchaus nicht alle in ihrem Einflusse auf den Culturfortschritt auch 
nur annähernd in gleichem Grade wirksam. Meiner Hauptaufgabe folgend, begnüge ich mich mit dem Hinweis darauf, daß zu diesen im erwähnten Sinne zurückstehenden Disciplinen auch die Krystallographie zu zählen ist.

Man weiß, daß diese Disciplin eine wesentliche Rolle als Grunddisciplin für die mineralogischen Wissenschaften spielt und für denjenigen Teil der Bergbaukunst, welcher die Ausbeutung des rohen Naturmaterials als sein Object hat.

Welcher Teil der Krystallographie kommt aber dabei in Betracht? Gerade derjenige, welchen die Krystallographie selbst aus der reinen Physik übernommen hat, und zwar in erster Linie die Gesetze der optischen Erscheinungen in Krystallen.

Wie aber aus der Benennung dieser Disciplin direct ersichtlich ist, hat sie zu ihrem Hauptobject die äußeren Krystallformen. Und in Wirklichkeit sind die meisten Kräfte der tätigen Specialisten dieser Wissenschaft wäbrend der nicht zu kurzen Geschichte derselben ganz besonders dieser Abteilung der Wissenschaft gewidmet, und zwar muß man zugestehen, ohne der Summe der verbrauchten Kräfte proportionale Resultate.

Die Anzahl der krystallographischen Arbeiten, welche in erster Linie der Formbeschreibung der Krystalle verschiedener Substanzen gewidmet wurden, ist kolossal; sehr oft kam sogar vor, daß einige Substanzen von vielen, sogar von sehr vielen Forschern untersucht wurden.

Nun hätte man zu erwarten, daß von außerhalb stehender Seite die Meinung entstände, daß, wenn eine Substanz, in guten Krystallen gegeben, zu einer so gut studierten gehört, es leicht wäre, dieselbe ihrer Form nach gut und leicht zu bestimmen.

Wie sonderbar dies auch klingt, wissen doch die Krystallographen sehr gut, daß dem nicht so ist. Der einzige Fall, in welchem die kolossale krystallographische Literatur zu Hilfe kommt, ist derjenige, wenn die Antwort gefordert wird, ob die vorliegende, gut auskrystallisierte Substanz wirklich dieselbe ist, welche vorausgesetzt wird, oder nicht.

Somit war die Krystallographie wirklich dienstfähig für die Mineralogie gewesen bis zu der Zeit, da die Gesamtsumme der Mineralien so hoch stieg, daß es schon selten gelingt, für jedes gegebene Mineral eine bestimmte Voraussetzung $\mathrm{zu}$ fassen. Als die Zahl der gut bestimmten Mineralien viel geringer war, konnte jeder erfahrene Mineraloge für jedes bestimmte gegebene Mineral einige wenige Voraussetzungen bilden und durch Winkelmessung diese Voraussetzungen verificieren resp. fallen lassen.

Meines Wissens aber kam es noch niemals einem Spezialisten der Krystallographie in den Sinn, jede Substanz überhaupt, und nicht allein die verhältnismäßig sehr arm vertretenen Mineralien, durch die Krystallform zu bestimmen.

Bei so kolossalem Kraftaufwand so geringe Resultate. Woher kommt dies? 
Einfach daher, daß für verschiedene Krystalle einer und derselben Substanz, bei sehr deutlich und historisch früh erkannter Constanz der respectiven Flächenwinkel, keine Constanz in den Combinationen sich feststellen läßt. Diese Veränderlichkeit ließ sich seit den ersten Schritten der Wissenschaft constatieren, sodab schon in dem ersten Stadium derselben sich immer mehr und mehr die Überzeugung aufdrängte, daß jede Substanz in bezug auf ihre Formen sehr veränderlich ist; fehlt aber die Constanz, so gibt es keinen festen Grund zu Bestimmungen.

Daraus wuchs die fast allgemeine Vorstellung, daß wir an jeder Substanz die verschiedenartigsten Formen beobachten können, je nach den äußeren Umständen, in welchen der Krystallisationsvorgang verläuft. Es verblieb im Resultat nur eine Constanz, daß für alle diese zufälligen Formen ein und dasselbe Axensystem gelten müsse, in welchem diese Formen rational zum Ausdruck kommen. Welches aber als dieses Axensystem zu wählen ist, blieb ganz gleichgültig.

Damit aber keine besonderen Schwierigkeiten daraus entstünden, daß verschiedene Forscher für eine und dieselbe Substanz verschiedene Axensysteme gebraucht hätten, wurde es stillschweigend als obligatorisch angenommen, daB jeder folgende Forscher derselben Substanz auch auf dasselbe Axensystem Bezug nimmt, welches, obgleich willkürlich, der erste Forscher erwählt hatte.

Somit blieb kein Platz für die Hoffnung bestehen, irgendwann die Krystallform der Substanzerkennung zugrunde zu legen.

Wenn einerseits, wie erwähnt, die Willkür des ersten Forschers in den Rang von etwas Obligatorischem gestelit wurde; so wurden andererseits, sogar für die ersten Erforscher jeder Substanz und ebenfalls stillschweigend, einige specielle Forderungen, als obligatorische, hervorgehoben, welche aber mit der Zeit und weiteren Entwicklung der Krystallographie etwas abgeändert wurden. Diese, keineswegs auf genau festgestellten Gesetzen fußenden Forderungen sollten nur eine Einheitlichkeit in den Beschreibungen erzielen.

Einerseits großer Raum zur Willkür, andererseits nicht auf genauen Gesetzen fußende obligatorische Forderungen! Es ist kaum nötig, zu erwähnen, daß weder Willkür, noch von vornherein aufgestellte Forderungen mit einer exacten Wissenschaft vereinbare Dinge sind.

Eine allgemeine Übersicht des so großartig angehäuften krystallographischen Materials ließ jedoch die Sache nicht so schlimm erscheinen, als es unmerklich $\mathrm{zu}$ fast allgemeinem Bewußtsein gekommen war.

Bei dieser Übersicht fiel es dem Verf. auf, daß, obgleich wirklich unter verschiedenen Umständen des Krystallisationsvorganges eine Veränderlichkeit in der Formenentwicklung einer und derselben Substanz sich kundgibt, doch durchaus nicht alles in diesem Vorgang gleich veränderlich ist, daß 
außer auftretenden und verschwindenden Formen es auch solche gibt, welche sich durch merkwürdige Constanz auszeichnen. Es ist wahr, daß der Grad der Entwicklung sogar dieser, constanteren Formen, nicht ganz beständig ist; in verschiedenen Fällen dominiert in ihrer Entwicklung bald die eine, bald die andere von ihnen, doch bleibt die Hauptsache bestehen - die relative Constanz dieser wenigen Formen, während die anderen eine viel geringere Beständigkeit aufweisen, bis zu solchen, welche durchaus als zufällige zu bezeichnen wären; unter letzteren kommen sogar solche vor, welche unter mehreren Tausenden gemachter Beobachtungen, sich nur einmal constatieren ließen, um im weiteren gar nicht mehr zum Vorschein zu kommen. Es sprang auch ins Auge, daß diese jedenfalls weniger wichtigen bis ganz zufälligen Formen, sehr oft auch unvollzählig zutage treten, und für die zufälligen ist es fast stets der Fall, daß sie durch eine einzige Fläche vertrelen erscheinen.

Als das gesamte krystallographische Material mehr oder weniger in Ordnung gebracht war, ließ dasselbe Schlußfolgerungen ziehen, welche den historisch entwickelten und oben erwähnten ganz entgegengesetzt waren. Aus demselben ist ersichtlich, daß die überwiegende Mehrzahl der Súbstanzen sich durch merkwürdige Constanz des Erscheinens der wichtigsten Formen auszeichnet. Es gibt zwar eine Reihe von Fällen, in welchen sogar diese beständigsten Formen eine Tendenz zu etwaiger Veränderlichkeit zeigen; diese Fälle sind aber eher als Ausnahmefälle aufzufassen.

Andererseits aber wissen wir jetzt sehr gut, daß auf die Resultate der Krystallisation verschiedene Momente, und ganz besonders Beimengungen in der Lösung, sich wirkend erweisen. Für'einige Substanzen haben wir solche Beimengungen kennen gèlernt, welche dem Auftreten einiger oder anderer Formen entgegentreten, und wenn diese sogar die Ausbildung der wichtigsten Complexformen unmöglich machen, so erscheinen ganz anormale Krystallisationen, in welchen überhaupt keine Formen in deutlicher Entwicklung auftreten. Solche Bildungen lassen sich natürlich nicht mehr zur Bestimmung der Substanz verwenden. Aber wir können auch den Krystallisationsvorgang absichtlich in günstigere Bedingungen stellen und mit dem Resultate, die Entstehung einer maximalen Combination hervorzurufen. Dies ist z. B. für die Krystallisation einer Substanz in Kugelform (welche ihr künstlich gegeben wird) der Fall, besonders wenn dabei noch die Lösung. stark übersättigt ist 1 ).

Noch lehrreicher ist die Schlußfolgerung, daß in der überwiegenden

1) Ich kann dabei auf die Arbeit Artemiew's: »Die Krystallisation der Kugeln als eine besondere Methode der krystallographischen Forschung « (diese Zeitschr. 48, 447) Bezug nehmen, wo nicht nur die zahlreichen Experimente des Verfs. selbst, sondern auch die respectiven Beobachtungen früherer Forscher zu finden sind. 
Mehrzahl der Fälle nur sehr wenige, und zwar die oben erwähnten wichtigsten Formen allein zum Vorschein kommen.

Dadurch erhält der Begriff der wichtigsten Complexformen einen ungewöhnlich demonstrativen Ausdruck. Ein rascher Überblick über die jetzt zusammengefaßten Tabellen führt zu dem Schlusse, daß in den meisten Fällen, und dabei nicht in einfacher Majorität derselben, sondern in überwiegender Mehrzahl die Anzahl der vertretenen Formen so gering ist, daß die Gesamtsumme der Flächen(-paare) die Zahl 10 nicht übersteigt.

Dementsprecbend haben wir z. B. für kubische Syngonie die geringste und für die trikline Syngonie die im Durchschnitt größte Vertretung der einfachen Formen.

Und für solche Krystalle erhält man fast stets einen und denselben Formencyclus, obgleich die Entwicklung verschiedener Formen (und sogar einzelner Flächen derselben Form), dementsprechend auch der sogenannte Habitus (die früheren Forscher, besonders unter den Mineralogen, sprachen sogar von »Typen «) der Krystalle sehr veränderlich sein kann.

Aus allem Gesagten geht der Begriff der wichtigsten Complexformen und zugleich das Gesetz der Formenentwicklung in der Reihenfolge der Wichtigkeit der Formen klar hervor.

Um die Überzeugung von der Gültigkeit eines Naturgesetzes zu gewinnen, gibt es im Gebiet der physikalischen Wissenschaften das allgemeine Verfahren: aus dem Gesetze logische Schlußfolgerungen zu ziehen und dieselben auf dem Wege der direkten Erfahrung zu prüfen.

Nun sind in dem Gebiete der Krystallographie sehr zahlreich die isomorphen Reihen vertreten. Ist aber das Gesetz der Formenentwicklung (in der Reihenfolge der Wichtigkeit der Formen) für alle Substanzen überhaupt gültig, so müssen auch in allen Gliedern isomorpher Reihen dieselben Formen vorwiegend vertreten sein, sodaß für alle Glieder der Reihe dieselben die gleichen sein müssen, wenigstens insofern dieselben von den äußeren Umständen der Krystallisation unabhängig sind.

Das beste Experimentum crucis in diesem Falle bezieht sich auf zahlreichst vertretene isomorphe Reihen. Ein Beispiel mit 20 Gliedern wiegt mehr als viele Beispiele mit zehn Gliedern, ein Beispiel mit 30 Gliedern um ebensoviel mehr gegenüber dem vorigen usf.

Nun zeichnet sich unter allen anderen ganz besonders eine isomorphe Gruppe durch ganz ungewöhnlich reiche Vertretung der Glieder aus; das ist die Gruppe der Doppelsulfate (resp. Selenate und Chromate) von der allgemeinen Formel $\left(\mathrm{XO}_{4}\right)_{2} \mathrm{NM}_{2} .6 \mathrm{H}_{2} \mathrm{O}$, wo $\mathrm{X}$ durch $\mathrm{S}$, Se und $\mathrm{Cr}, \mathrm{N}$ durch $\mathrm{Mg}, \mathrm{Mn}, \mathrm{Fe}, \mathrm{Ni}, \mathrm{Co}, \mathrm{Cu}, \mathrm{Zn}, \mathrm{Cd}, \mathrm{M}$ durch $\mathrm{K}, \mathrm{Rb}, \mathrm{Cs}, \mathrm{NH}_{\mathbf{4}}, \mathrm{Tl}$ vertreten sind.

Von dieser zahlreichsten unter den mir bekannten Gruppen sind schon 


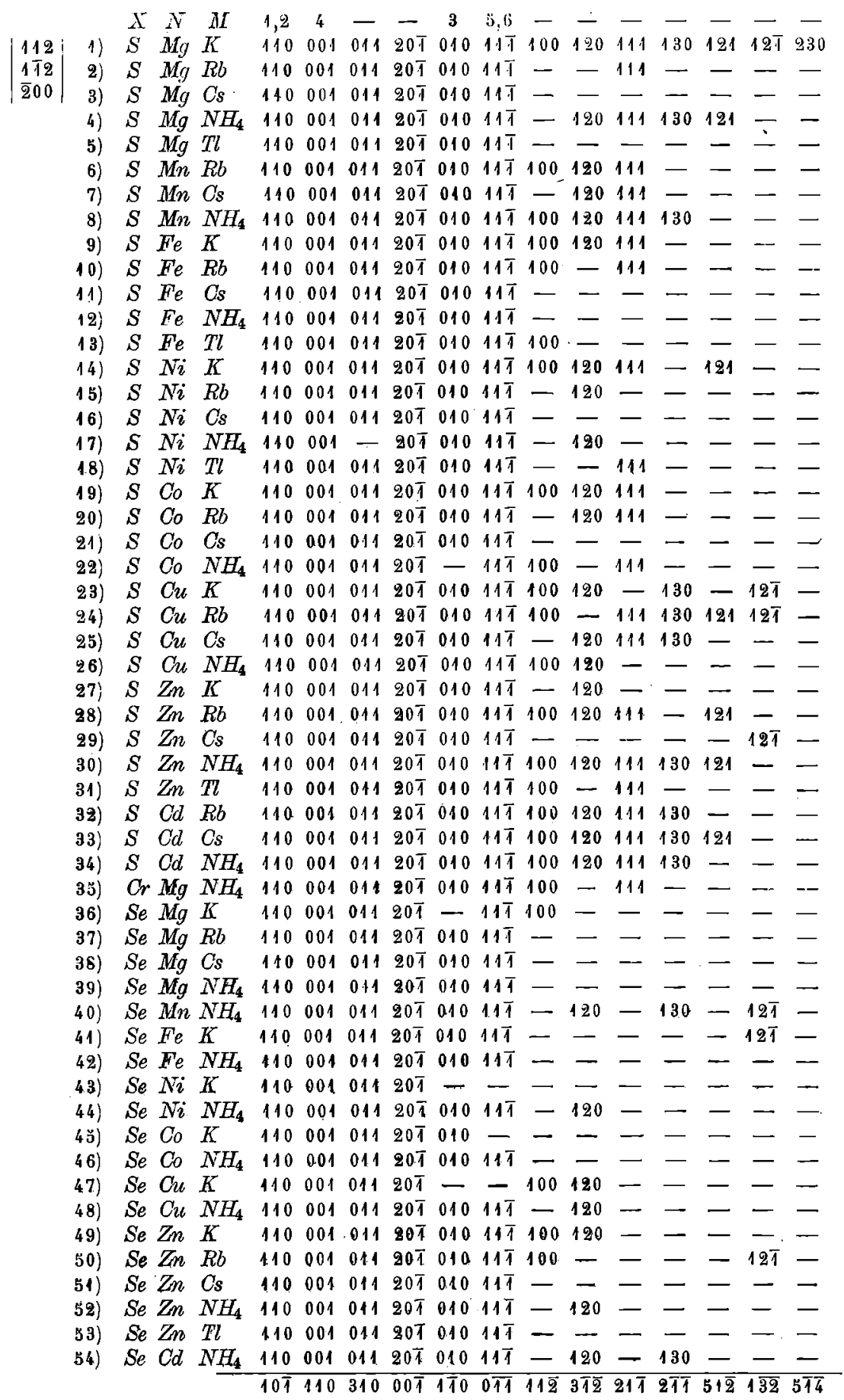


54. Glieder krystallographisch erforscht, und ich stelle nun die Hauptresultate dieser Forschung tabellarisch auf S. $5 / 8$ zusammen $\left.{ }^{1}\right)$.

Links oben ist die Determinante für die Transformation der Indices in die richtige Aufstellung angegeben.

Ich glaube, daß es eine anschaulichere Illustration für das in Rede stehende Gesetz nicht geben kann.

In der obersten Zeile dieser Tabelle ist die theoretische Reihenfolge nach der Wichtigkeit der ersten sechs Flächen(-paare) angegeben. Diese Reihenfolge steht, wenn auch nicht ganz vollständig, so doch mit sehr großer Annäherung mit der beobachteten im Einklange.

Berücksichtigt man, daß in dieser Tabelle die Formen angegeben sind, welche überhaupt für jede Substanz zur Beobachtung kamen, ohne darauf Rücksicht zu nehmen, wie oft die betreffende Form wirklich bei der Krystallisation angetroffen wurde, kann man sagen, daß somit die Darstellung der wichtigsten constanten Formen etwas übertrieben ist, d. h. nicht sämtliche constante Formen dieser Tabelle wirklich als die wichtigsten für jeden Complex, einzeln genommen, gelten können. Trotzdem aber ist schon diese Anzahl ziemlich gering.

Es kommen nicht selten Fälle vor, in welchen ein guter Aufstellungswert sich nur dann ermitteln läßt, wenn der Reihe der wichtigsten Structur-

$$
\text { Is omorphe Gruppe } M X Y Z \text {. }
$$

\begin{tabular}{|c|c|c|c|c|c|c|c|c|c|c|c|}
\hline & $M$ & & $Y$ & $Z$ & 0,67 & 00 & 1,48 & 44 & 2,03 & 2,43 & 0,45 \\
\hline 1) & $\mathrm{NH}_{4}$ & $J$ & $J$ & $J$ & 110 & & 102 & 011 & & $001 *$ & - \\
\hline z) & $R b$ & $C l$ & $C l$ & $B r$ & 0 & 00 & 102 & 011 & 010 & - $^{*}$ & - \\
\hline 3) & $R b$ & $C l$ & $B r$ & $B r$ & 110 & $-*$ & 102 & 011 & 010 & $001^{*}$ & - \\
\hline 4) & $R b$ & $\mathrm{Cl}$ & $C l$ & $J$ & - & $00^{*}$ & 102 & 011 & - & - $^{*}$ & - \\
\hline 5) & $R b$ & $B r$ & $B r$ & $B r$ & 110 & & - & 041 & 010 & $-{ }^{*}$ & .021 \\
\hline 6) & $R b$ & $\mathrm{Cl}$ & $B r$ & $J$ & - & & 102 & 011 & 040 & - $^{*}$ & - \\
\hline 7) & $R b$ & $B r$ & $B r$ & $J$ & 110 & * & 102 & 011 & - & $001 *$ & - \\
\hline 8) & $R b$ & $J$ & $J$ & $J$ & 110 & $-^{*}$ & 102 & 011 & 010 & $001^{*}$ & 021 \\
\hline 9) & $C s$ & $C l$ & $C l$ & $B r$ & 110 & - & - & 011 & - & $001 *$ & - \\
\hline 0) & $C s$ & $\mathrm{Cl}$ & $\mathrm{Cl}$ & $J$ & 110 & 100 & 102 & 011 & - & $001^{*}$ & 021 \\
\hline 1) & $C s$ & $B r$ & $B r$ & $B r$ & 110 & - & - & 011 & 010 & - $^{*}$ & 021 \\
\hline 2) & $C s$ & $C l$ & $B r$ & $J$ & 110 & 100 & 102 & 011 & - & $001 *$ & 021 \\
\hline 13) & $C s$ & $B r$ & $B r$ & $J$ & 110 & 100 & 102 & 011 & - & $001^{*}$ & 021 \\
\hline 14) & $C s$ & $B r$ & $J$ & $J$ & 110 & 100 & 102 & 011 & 010 & $001^{*}$ & - \\
\hline 15) & $C s$ & $J$ & $J$ & $J$ & 110 & 100 & 102 & 011 & 010 & $001 *$ & 021 \\
\hline \multirow[t]{2}{*}{$16)$} & $T l$ & $J$ & $J$ & $J$ & - & 100 & 102 & 0.11 & 010 & $001^{*}$ & - \\
\hline & & & & & 172 & 001 & 111 & 100 & 170 & 110 & $3 \bar{\pi} 0$ \\
\hline
\end{tabular}

1) Natürlich sind alle diese Glieder auch in der Chemischen Krystallographie von Groth 2, 509 gesammelt. 
formen diejenige der vollkommenen Spaltbarkeit zugerechnet wird. Dieser Umstand macht die Prüfung auf Spaltbarkeit unentbehrlich.

Als das beste Beispiel dafür kann die Tabelle auf S. 519 unten dienen, in welcher die Flächen einer vollkommenen Spaltbarkeit durch * angemerkt sind.

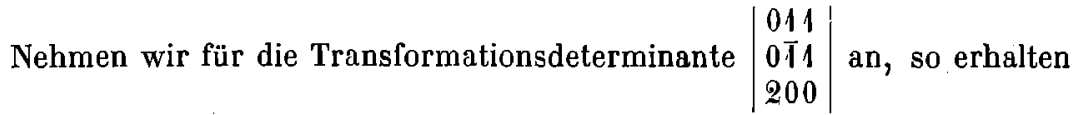
wir für die letzte Zeile die angegebenen Formensymbole, und für die erste Zeile die angegebene theoretische Reihenfolge der Formen nach ihrer Wichtigkeit; durch keine andere Transformation wird ein größerer Aufstellungswert erhalten; hierbei ist aber unbedingt notwendig, die Flächen der vollkommenen Spaltbarkeit in Rücksicht zu ziehen. Das Complexsymbol ist dabei $\begin{gathered}4 \mathrm{~h} \\ 52 \\ -2 .\end{gathered}$

Jeder Krystallograph weiß, daß der Begriff des Isomorphismus kein absoluter ist und lediglich auf die größere Annäherung des betreffenden Complexes hinweist. Der Grad der Annäherung kann auch weiter aufgefaßt werden, und falls dieselbe außerhalb der Grenzen desjenigen hinaus kommt, was man üblich dem Isomorphismus zuerteilt, so gelangen wir zu dem von Groth eingeführten Begriff der Morphotropie. Nun ist also zu erwarten, daß, wenn auch nicht so rein, das hier in Rede stehende Gesetz der Formenentwicklung auch in diesem Falle zur Äußerung kommen wird.

Inwiefern dies zustande kommt, will ich an einem Beispiele darstellen, und da die betreffenden Krystalle zur hexagonalen Syngonie und zum kubischen Typus gehören (also trigonal sind), so stelle ich die hierzu gehörenden Hauptzahlen (Winkelgröße 100:111) zusammen, um den Grad der Annäherung zu charakterisieren, und füge zugleich die beobachtete Combination hinzu:

Die betreffenden Substanzen sind $\left.{ }^{1}\right)$ :

\begin{tabular}{|c|c|c|c|c|c|c|c|}
\hline$H g_{6}$ & $C l_{13}$ & $\mathrm{NH}_{3}\left(\mathrm{C}_{2} \mathrm{H}_{5}\right)$ & 100 & 110; & - & 一 & $48^{0} 59$ \\
\hline$H_{g_{6}}$ & $C l_{13}$ & $\mathrm{NH}\left(\mathrm{C}_{2} \mathrm{H}_{5}\right)_{3}$ & 100 & 170 & 110 & 111 & \\
\hline$B g_{6}$ & $C l_{13}$ & $\mathrm{NH}_{3}\left(\mathrm{C}_{3} \mathrm{H}_{7}\right)$ & 100 & $1 \overline{0} 0 ;$ & - & 111 & 4955 \\
\hline$H g_{6}$ & $C l_{13}$ & $N\left(C_{2} H_{5}\right)_{4}$ & 100 & $1 \overline{1} 0 ;$ & 110 & 111 & 50 \\
\hline$H g_{6}$ & $\mathrm{Cl}_{13}$ & $\mathrm{NH}\left(\mathrm{CH}_{3}\right)_{3} \cdot \mathrm{H}_{2} \mathrm{O}$ & 100 & 1T0; & - & 111 & 51 \\
\hline$H g_{6}$ & $C l_{13}$ & $N\left(\mathrm{CH}_{3}\right)_{3}\left(\mathrm{C}_{2} \mathrm{H}_{5} \mathrm{O}\right)$ & 100 & $1 \bar{T} 0 ;$ & 110 & 111 & 5146 \\
\hline
\end{tabular}

Die wichtigeren Formen, nach den Angaben der Verff., sind von den weniger wichtigen durch Semicolon abgetrennt.

1. Die ersten fünf Substanzen finden kurze Beschreibung auch in Groth's Chem. Krystallogr. 1, 393 ; die letzte ebenda 3, 102. 
Man hälte schwer entscheiden künnen, ob der Grad der Annäherung in diesem Falle nicht schon dem Begriff des Isomorphismus im engeren Sinne Genüge leistet, obgleich in chemischer Hinsicht hier schon sehr große Abweichungen $\mathrm{zu}$ sehen sind, besonders für die letzte Verbindung in dieser Reihe (Cholinchloromercuriat). Es ist aber nicht zu leugnen, daß hier nicht nur in den Grundwinkelgrößen, sondern auch in der Combination (also Formenentwicklung) große Annäherung vorhanden ist.

$\mathrm{Zu}$ diesen stehen in großer Annäherung noch folgende drei Substanzen:

\begin{tabular}{|c|c|c|c|c|c|c|c|}
\hline$H g_{6}$ & $C l_{13}$ & $\mathrm{NH}_{2}\left(\mathrm{C}_{2} \mathrm{H}_{5}\right)_{2}$ & 110 & $11 \pi$ & $1 \pi 0$ & 111 & $49^{0} 48^{\prime}$ \\
\hline $\mathrm{Hg}_{6}$ & $C l_{13}$ & $N\left(C H_{3}\right)_{4}$ & 110 & $11 \pi$ & $1 \bar{T} 0$ & 111 & \\
\hline$H g_{6}$ & $C l_{13}$ & $N\left(C H_{9}\right)_{2}\left(C_{2} H_{5}\right)_{2}$ & 110 & 141 & $1 \bar{T} 0$ & 111 & \\
\hline
\end{tabular}

Doch haben wir hier in der Combination eine nicht zu übersehende Abweichung von der vorigen, und zwar in der stetigen Anwesenheit der Form $(11 \bar{T})$, welcher, nach der Angabe der Verff., größere Bedeutung zukommt, denn diese wird von ihnen auf den zweiten Platz gestellt und die größere Flächenentwicklung derselben erwähnt.

Aus den von der Theorie der Krystallstructur entwickelten Gründen wird diesen drei Substanzen eine andere Hauptstructurart (und zwar die dodekaëdrische) zugeschrieben werden müssen, als den vorigen (hexaëdrische Hauptstructurart).

Somit führt uns die überwiegende Mehrzahl des angehäuften Erfahrüngmaterials zu einer Schlußfolgerung, welche derjenigen des ersten Stadiums unserer Wissenschaft direct entgegengesetzt ist; zugleich aber lehrt uns dieses Material den Begriff der Reihenfolge der Wichtigkeit der Formen hoch zu schätzen.

Auf Grund dessen können wir neue, aber nicht mehr willkürliche, sondern gut motivierte Forderungen an die Krystallbeschreibung stellen, welche die Gesetze der Krystallbildung nicht außer acht lassen soll.

Man muß bei dieser Beschreibung nicht nur wenige, sondern eine müglichst große Anzahl Krystalle zugrunde legen und deren Combinationen zusammenstellen, um daraus, wenn auch nur annäherungsweise, den statistischen Wert der beobachteten Formen auszuziehen und anzugeben.

Glücklicherweise kamen viele Autoren der Krystallmessung dieser Forderung, wenn auch in elementarer Weise, nach, indem besondere Erwähnung von den constanten, seltenen und ganz zufälligen Formen gemacht wird. Den letzteren kommt natürlich keine bestimmende Bedeutung zu. Vielleicht aber eine noch größere Anzahl der Autoren macht in dieser Hinsicht keine Andeutung. Für so beschriebene Krystalle entsteht, wie jetzt begreiflich wird, eine Schwierigkeit in der Entscheidung, welchen Formen die größte und welchen geringere Bedeutung zukommt, falls überhaupt die Anzahl der zur Beobachtung gekommenen. Formen nicht die minimale ist. Dann 
verschwinden sogar alle Schwierigkeiten von vornherein, weil alle beobachteten Formen zu den wichtigsten gehören müssen.

In den von unserer Schule 1) zusammengefaßten und sogar veröffentlichten Diagrammen wird diesen Forderungen dadurch Genüge geleistet, da $B$ an die Stelle der Punkte - der Pole der betreffenden Flächen besondere Zeichen gesetzt werden: für solche Formen, welche wenigstens in $90 \%, \bigotimes$ in $50 \%, \bigotimes$ in $25 \%, \oplus$ in $10 \%$ aller beobachteten Combinationen der untersuchten Substanzen constatiert wurden; die selteneren werden einfach durch $O$ und die ganz zufälligen Flächen werden durch $\times$ angemerkt.

Jedenfalls wird aus dem Gesagten ersichtlich, daß die Entwicklung der Formen jeder krystallinischen Substanz keine zufällige ist und sich für die wichtigsten durch einen höheren Grad der Constanz auszeichnet.

Die allgemeine Erfahrung gibt uns somit auf die Frage über die Möglich- keit der Substanzbestimmung auf Grund der Krystallformen derselben eine bejabende Antwort.

Bis jetzt wurden hier lediglich die reinen Tatsachen berücksichtigt. Nun ist aber keine Wissenschaft möglich ohne eine im Grunde derselben stehende Theorie, welche den Reichtum der von ihr studierten Tatsachen in einfacherer Darstellung vereinigt. Sonst wäre es ganz unmüglich, in der unzähligen Reihe der einzelnen Beobachtungen sich zu orientieren, und allein eine gute Theorie ist fähig, klare Übersicht in dieser unüberwindlichen Mehrheit zu geben.

Der theoretischen Krystallographie Iiegt die Krystallstructurtheorie zugrunde; deren erste Anlage wurde schon von dem ersten ihrer wissenschaftlichen Vertreter, Ha üy, angedeutet, weiter durch Delafosse, Frankenheim, Bravais und Sohncke bearbeitet, bis endlich durch die Ausarbeitung der mathematischen Theorie über reguläre Plan- und Raumverteilung und mit Zuhilfenahme einiger Sätze und Constructionen, ebenso wie specieller Lehren der neueren Geometrie (in der ersten Linie der Syngonielehre), die Theorie bis zu einem Punkte entwickelt wurde, daß sie fähig geworden ist, durch die Erfahrung geprüft zu werden, und die weiteren Schritte Hand in Hand mit der Erfahrung verknüpft vorangingen.

Welche Antwort haben wir jetzt auf die erste, durch das Beobachtungsmaterial angeregte Frage, welche Flächen jedes Krystallcomplexes die wichtigsten sind?

Nun hat das directe Experiment bewiesen ${ }^{2}$, daß die wichtigsten die Flächen von größter Löslichkeit sind, und die Theorie hat uns gelehrt, daß

1) Des Berginstituts in St. Pelersburg.

2. Die Annalen des Berginstituts zu St. Petersbarg 1, 81: Dies stimmt auch mit den theoretischen Betrachtungen von G. Wulff überein. 
die lüslichsten Flächen diejenigen von compactester Punktbesetzung sind, d. h. von größter reticulärer Dichtigkeit 1 ).

Wollen wir irgendeine von der Theorie zulässige Structurart voraussetzen, so werden wir somit auf theoretischem Wege in den Stand gesetzt, nicht nur die Reihenfolge der Wichtigkeit der Formen zu bestimmen, sondern sogar diesen Wert zahlenmäßig auszudrücken, was gegenwärtig durch das Quadrat der reticulären Dichtigkeit geschieht ${ }^{2}$ ).

Nun müssen wir von vornherein die Begriffe der theoretischen und der wirklichen Reihenfolge der Formen auseinander halten.

Der erste Begriff kann nicht in jedem gegebenen Falle direct in dem Verfahren verwirklicht werden, da außer reticulärer Dichtigkeit noch einige andere Momente darin wirksam sind, und dabei solche, welche wir zurzeit zahlenmäßig zu schätzen noch nicht imstande sind. Hierzu gehören nicht nur die äußeren Umstände, unter welchen die Krystallisation vor sich geht, sondern auch die noeh wenig bekannten inneren Verhältnisse der Krystallmolekel (etwa die Lagerung ihrer elektrischen Pole u. dgI.), welche jeder gegebenen Substanz einen Grad der Individualität zuerteilen.

Unter " theoretischer Reihenfolge " verstehen wir die leicht bestimmbare Reihenfolge der reticulären Dichtigkeiten; hier ist also nur ein Moment berücksichtigt, obgleich, wie die Erfahrung lehrt, dieses Moment zwar das wichtigste unter allen anderen ist, aber nicht das einzige. Die Erfahrung hat nämlich gezeigt, daß wir in den individuellen Fällen regelmäßig einige Abweichungen der tatsächlichen Reihenfolge von der wirklichen finden; in statistischem Ausdruck erweisen sich die beiden Reihenfolgen als vollstăndig übereinstimmend.

Es ist zwar auch eine ziemlich große Anzahl von Einzelfällen constatiert, in welchen die beiden Reihenfolgen, also die theoretische und die wirkliche, fast oder ganz genau übereinstimmen. Im großen und ganzen ist dies aber nicht der Fall, sodaß die ersteren eher als Ausnahmefälle aufzufassen sind.

Gerade aber die von der Erfahrung gegebene Abweichung dieser beiden Reihenfolgen erweist sich von größter Wichtigkeit für die Substanzbestimmung, welche auf dem Studium der Formen beruht. Gerade diese Abweichung erteilt jeder gegebenen Substanz einen Charakter der Individualităt, und diese Individualitätskennzeichen tragen besonders zur schärferen Unterscheidung zwischen zwei, sonst in bezug auf Formen sehr nahestehenden Substanzen bei.

1) Jetzt schon in fortgeschritteneren Elementarbuichern der Krystallographie angegeben.

2) Das letzte und einfachste Verfahren von Herrn Sok olow und Artemiew publiciert in den Annalen des Berginstituts 2, 333 und später übersetzt in dieser Zeitschr. 48, 377. 
Ein besonders einfaches und lehrreiches Beispiel solcher Individualität der Substanz ist das des Quarzes.

Obgleich die Krystalle dieser Substanz der trigonalen Hyposyngonie (und zwar der trapezoëdrischen Klasse) angehören, ist die Zugehörigkeit zum hypohexagonalen Typus sehr scharf ausgesprochen, und deswegen müssen die Flächen durch viergliedrige Symbole ausgedrückt werden.

Ganz scharf kommen auch die wichtigsten Complexflächen zum Vorschein, und zwar die Formen $\{0110\},\{1110\}$ und $\{110 T\}$; alle übrigen, außerordentlich zahlreich angegebenen Formen sind von ganz untergeordneter Bedeutung.

Der betreffende Complex wird durch das Symbol $+54^{6} 47^{\prime}$ ausgedrückt, wo die Hauptzahl die Winkelgröße (1000):(1110) bezeichnet; die obere Zahl 6 auf die Zugehörigkeit des Complexes zum hypohexagonalen Typus hinweist und das +Zeichen ausdrücken soll, daß die betreffende Hyposyngonie die trigonale ist und die zweizähligen Symmetrieaxen nicht senkrecht zu Flächen des Hauptprisma, sondern diagonal stehen.

Nun erhält man die theoretische Reihenfolge für die Flächen(-paare): für $(1000)-4,0$, für die drei folgenden $(0110)-2,47$, und endlich für alle sechs folgenden (1110) und (110T) erhält man den Wert für die reticuläre Dichtigkeit 1,54 ; allen übrigen Formen kommt schon ein viel niedrigerer Wert zu.

Nun sieht man, daß in diesem so scharf ausgeprägten individuellen Complexe gerade die theoretisch wichtigste Fläche (1000) stets 1) abwesend ist. Darin besteht das schärfste Kennzeichen der Individualität der Quarzsubstanz. Dieser Fall ist von besonders großer Wichtigkeit, da zugleich die Richtigkeit der Aufstellung ebenfalls mit besonderer Schärfe zum Ausdruck gekommen ist, indem außer dieser ersten Form die folgenden (in der theoretischen Reihenfolge) Glieder vom zweiten bis zum zehnten stets vorhanden sind und zweifellos auch in der wirklichen Vertretung die wichtigsten sind.

Damit ist also sehr genau der Beweis erbracht worden, daß in den reellen Complexen sogar die Flächen von größter reticulärer Dichtigkeit nicht zum Vorschein kommen können. (Natürlich ist dieser Fall nicht der einzige; und in den abgefaßten Tabellen treffen wir solcher eine, obgleich sehr schwach vertretene, Reihe). Jetzt braucht man schon keinen Beweis mehr, daß, wenn auch die ihrer Wichtigkeit nach ersten Formen in der wirklichen Vertretung nicht erscheinen können, a fortiori die Fälle möglich

1) Von ganz zufälligen Angaben des Erscheinens dieser Form ist ganz abzusehen; wäre diese Form nicht so außerordentlich zufällig erschienen, so würde von deren Auftreten keine besondere Angabe nötig, da jedem Mineralogen viele Tausende Krystalle von Quarz vorkommen. 
sind, in denen diejenigen Flächen nicht erscheinen, welchen in der Reihenfolge der zweite, dritte oder noch weitere Platz zukommt.

Wie nun aber den Beweis erbringen, daß trotz des Fehlens der wichtigsten Form der Complex des Quarzes durch das gegebene Symbol richtig ausgedrückt wird?

Dazu gehört eine sehr einfache Rechnung. Solche Rechnungen sind sehr zahlreich in meinen früheren und ganz besonders in der Grundarbeit "Allgemeinste Krystallisationsgesetze und die darauf fußende eindeutige Aufstellung der Krystalle ${ }^{1}$ ) aufgeführt worden, obgleich damals die Rechnung noch mit grober Annäherung ausgeführt wurde, während wir jetzt dieselbe schon mit graphischer Genauigkeit vollführen.

Als den ideellen (resp. theoretischen) Wert für die Summe der ersten neun reticulären Dichtigkeiten erhalten wir $J=4,0+3 \times 2,47+5 \times$ $1,54=19,11$ und für die Summe der Dichtigkeiten der neun beobachteten Flächen $R=3 \times 2,47+6 \times 1,54=16,65$; also $\frac{R}{J}=0,90$.

Diese Zahl - der Aufstellungswert - gibt Antwort auf die gestellte Frage, indem angenommen wird, daß, wenn für dieselbe Formenreihe eine solche Aufstellung existiert, bei welcher sich für diese Zahl ein größerer Wert bestimmen läßt, dann die gegebene Aufstellung für unrichtig erklärt und als die richtige die neue aufgefaßt werden müßte.

Überhaupt ist zur Bestimmung der reticulären Dichtigkeiten durchaus nötig, irgendeine Aufstellung anzunehmen; man hat alsdann für jede solche die Rechnung der eben angezeigten Art auszuführen, und erhält auf diese Weise für jede Annahme einen bestimmten Aufstellungswert. Nun gilt es als selbstverständlich, daß diejenige Auffassung des Krystallcomplexes als die richtige anerkannt werden muß, für welche der Aufstellungswert der maximale ist.

Dies gilt absolut für die Complexe, für welche die Hauptfläche (im Falle des Quarzes 1000, für tetragonaloïde Krystalle 001, für trigonaloïde 111) zu der Axe der Hauptzone (deren Symbol dasselbe ist wie das der Hauptfläche) genau senkrecht steht, mit folgender Ausnahme für die Krystalle, an welchen eine Abweichung in dem beobachteten Winkel des Hauptdrismas von dem theoretischen sich kund gibt.

Der Begriff der Hauptfläche und der Hauptzone für sämtliche Krystallcomplexe fußt gerade auf der allgemeinen Erfahrungstatsache, daß es stets in den Krystallcomplexen wenigstens eine Zone gibt, für welche die Annäherung des Prismenwinkels an den Wert $45^{\circ}$ (tetragonaloïde) resp. $60^{\circ}$ (hexagonaloïde) statthat. Speciell für die Krystalle der kubischen Syngonie haben wir nicht eine, sondern eine Reihe solcher Zonen genau verwirklicht,

1) Diese Zeitschr. 38, 321. 
für die pseudokubischen kommt also dasselbe in ungenauer Verwirklichung vor, weshalb solche Complexe eine Ausnahme bilden und als Complexe ohne Hauptzonen resp. ohne Hauptflächen bezeichnet werden können (wie es auch in alter Zeit geschah).

Jede allgemeine Tatsache wird aber durch das Wort »Gesetz « bezeichnet. In diesem Falle besteht das Wesen des Gesetzes darin, daß alle Krystallcomplexe überhaupt sich zwei Grenzen nähern, welche als die Complexe der tetragonalen resp. der hexagonalen Syngonie bezeichnet werden. Infolgedessen habe ich das betreffende Gesetz als Limitgesetz der Krystallographie aufgefaßt.

Wenn wir z. B. einen pseudokubischen Complex betrachten, so sind unter seinen Zonen eine Reihe solcher auszuzeichnen, welche den Hauptzonen der tetragonalen resp. der hexagonalen Syngonie sich in den Winkelverhältnissen nähern; aber für verschiedene Zonen ist der Grad dieser Annäherung verschieden, und natürlich ist auf Grund des Limitgesetzes diejenige Zone besonders auszuzeichnen, welche im höchsten Grade die Limitwinkelverhältnisse verwirklicht. Falls aber der Krystallcomplex nicht der echt kubische ist, so kann man im allgemeinen in demselben eine einzige Zone vor allen übrigen auszeichnen, und gerade diese wird als die Hauptzone bezeichnet. Also allein für die echt kubischen Krystalle erhält diese Frage eine unbestimmte Auflösung, da alle betreffenden Zonen der Reihe nicht nur eine Annäherung, sondern schon eine genaue Verwirklichung der Limitverhältnisse aufweisen. Aus diesem Grunde sind die echt kubischen Krystalle von sämtlichen übrigen auszuscheiden und als eine besondere Gruppe zu betrachten.

Ist also der gegebene Complex kein echt kubischer, und würde der Grad der Annäberung der pseudosyngonischen Zonen an die Limitzonen nicht berücksichtigt, so würde eine Unbestimmtheit daraus entstehen. Die Annahme einer derselben als die Hauptzone würde an einer Willkür leiden, was natürlich in jeder exacten Wissenschaft unzulässig ist. Es muB also ein zahlenmäBiger Ausdruck gegeben werden, welcher dieser Unbestimmtheit resp. Willkür Rechnung trägt, $d$. h. dieselbe beseitigt auf echt objectivem Grunde. Die Annahme eines solchen Rechnungsfactors ist also eine unbedingte Notwendigkeit für unsere Wissenschaft.

Diesen Factor finde ich in der Function $\cos \gamma$, wo $\gamma$ die Abweichungsgröße des Prismenwinkels der für die Hauptzone angenommenen Zone von dem betreffenden Limitwinkel (900 für tetragonale und $60^{\circ}$. für hexagonale) ist. Gerade die Hälfte dieses Winkels bildet die untere Zahl des Complexsymbols. Folglich ist es, um jede Willkür und Unbestimmtheit zu beseitigen, unbedingt nötig, in allen diesen Fällen die den Aufstellungswert ausdrückende Zahl mit $\cos \gamma$ zu multiplizieren. Nimmt also jemand für 
die Hauptzone nicht die richtige, sondern eine andere, so wird die von demselben berechnete Zahl kleiner als für die richtige Annahme.

Für die ideellen Krystallcomplexe, wie z. B. denjenigen des Quarzes, ist dieser Factor natürlich gleich der Einheit.

Aus demselben Grunde und auf dieselbe Weise sind auch die anderen Abweichungen in den Winkelverhältnissen von denen. der ideellen Krystalle zu berücksichtigen und durch Factoren im endgültigen zahlenmäßigen Ausdruck zu verwirklichen.

Bei ideellen Krystallen haben wir nämlich den Fall, daß stets die Axe der Hauptzone zur Hauptfläche senkrecht steht. In Complexen, wo dies nicht der Fall ist, ist ebenfalls der Abweichungsgröße Rechnung zu tragen. Dieser Fall bezieht sich aber nur auf monokline und trikline Complexe, und die Abweichungswinkelgrößen werden als monokline resp. trikline Verschiebungen unterschieden, und deren Größen finden ebenfalls in dem Complexsymbol Platz. Davon wird aber weiterhin ausführlicher die Rede sein.

Jetzt sehen wir, daß die Aufgabe der richtigen Auffassung eines gegebenen Krystallcomplexes in hohem Grade erleichtert ist, da wir jetzt erfahrungsgemäß wissen, daß jeder solche sich einer der ideellen Abteilungen des Krystallreiches nähern muß. Folglich gehört zu dieser Bestimmung nur eine geübte Ablesung der direct bei der Krystallmessung abgefaßten Diagramme (welche am zweckmäßigsten in gnomoster eographischer Projection auf den stereographischen Netzen zu entwerfen sind). Ist das Auge in diesem Lesen der Diagramme genügend geübt, so werden (wenigstens in den überaus meisten Fällen) sogleich nur sehr wenige Voraussetzungen zulässig, und wenn nicht von vornherein klar ist, welche Aufstellung die richtige ist, so sind also diese zwei oder drei Annahmen auf rechnerischem Wege zu prüfen, wie eben erklärt wurde. Inwiefern dabei ein eindeutiges Resultat herausspringt oder nicht, insofern ist die richtige Aufstellung als endgültig constatiert resp. noch zweifelhaft und der rechnerischen Verification bedürftig zu betrachten.

Aber es sind noch einige besondere Verhältnisse zu berücksichtigen, damit in denjenigen Fällen, wo zwei oder mehre re, vom allgemeinen Standpunkt aus gleichwertige, Aufstellungen sich ergeben, für welche man also auf rechnerischem Wege genau dieselben bestimmenden Zahlenwerte erhält, diése auseinander zu halten und eine davon als die anerkannt richtige zu schätzen ist. Da aber diese Verhältnisse umständlich genug in dieser Zeitschrift, und zwar in den Arbeiten »Paralleloëder in kanonischer Form und deren eindeutige Beziehungen zu Raumgittern (diese Zeitschr. 46, 245) und »Vollendung in der Entwicklung des Begriffs des kanonischen Paralleloëders « (diese Zeitschr. 48, 400) besprochen worden sind, so glaube ich hier mich mit dem Hinweis auf dieselben begnügen zu können.

Jetzt kehren wir einen Moment wieder zu der S. 518 angegebenen Tabelle 
mit 54 isomorphen Gliedern zurück. In der unteren Zeile dieser Tabelle sind die der als richtig anerkannten (trigonaloïden) Aufstellung zukommenden Indices angeführt. Aus der Reihenfolge der wichtigsten Formen ersieht man sogleich, daß die diesem Falle entsprechende Hauptstructurart die oktaëdrische ist, für welche den Formen, welche durch zwei ungerade Indices ausgedrückt werden, die doppelte reticuläre Dichtigkeit zukommt. Nun siebt man, daß die in der Wirklichkeit festzustellende Reihenfolge der theoretischen sehr nahesteht, indem alle theoretisch wichtigsten Formen in sämtlichen Complexen dieser Reihe wirklich vertreten sind. Aber aus der Tabelle ersehen wir zugleich als die Individualität dieser Complexe, das stetige Auftreten der theoretisch viel weniger wichtigen Form $\{310\}$. Das Auftreten derselben ist bei der Erkennung der Substanzen dieser großen Reihe also besonders wichtig; sonstige Formen von geringerer Bedeutung gehen aber in ihrem Auftreten sehr auseinander.

Nun können wir aus allem Vorherstehenden die ganz bestimmte Schlußfolgerung ziehen, daß, wenn nicht in der überwiegend größten, so wenigstens in der großen Mehrheit der Fälle, wirklich eine hinreichende Constanz in der Formenentwicklung sich kundgibt, um dieselbe zur Substanzbestimmung benutzen zu können. Dazu gehören nicht nur die theoretisch wichtigsten, sondern teilweise auch weniger wichtige Formen, deren Constanz zur individuellen Charakteristik der Substanzen beiträgt.

Es kann vorkommen, daß in diesen oder jenen Fällen diese Kennzeichen zu nicht vollständig eindeutigem Resultat führen, sodaß unter einer geringen Anzahl von Substanzen Zweifel entstehen kann. Dazu trägt besonders die nicht ganz genaue Ausbildung der Krystallflächen bei; in manchen Fällen können die erhaltenen Messungszahlen (genauer zu sagen die daraus ermittelten Durchschnittszahlen) nicht nur in den Grenzen von einigen Minuten, sondern sogar in den Grenzen von einigen Graden zweifelhaft werden.

In allen diesen, übrigens sehr oft vorkommenden Fällen kommen andere individuelle Eigenschaften der Substanzen zu Hilfe, wie z. B. die Farbe, das specifische Gewicht, der Schmelzpunkt und namentlich in erster Linie die chemischen, welche durch die einfachsten chemischen Proben geprüft werden können.

Es ist leicht zu begreifen, daß, wenn dabei nur wenige Substanzen zu unterscheiden sind, die raschesten und ungenauesten Verfahren zum Zwecke führen können und sich für die Bestimmung entscheidend erweisen.

Wie jetzt hinreichend erklärt wird, führt uns zu dieser Ausscheidung von sehr wenigen Substanzen unter der colossalen Anzahl aller übrigen, die Anwendung der verhältnismäßig einfachen Verfahren, welche von der Theorie der Krystallstructur dictiert werden. Und in der Tat hat die specielle Prüfung mittelst dieser Verfahren zum Resultat geführt, daß sogar über $75 \%$ 
der zur Prüfung gekommenen unbenannten Substanzen auf diese Weise richtige Bestimmungen erhalten haben.

So entstand die krystallochemische Analyse.

Die erste Anlage wurde für dieselbe durch die Publication des Werkes „Kritische Übersicht der Formen des Mineralreiches « (1902) geschaffen. Seitdem konnte man auf diesem Wege die Mineralien bestimmen ${ }^{1}$ ).

Gerade auf Grund dieser Arbeit wurde weiter verfahren, bis schon im Jahre 1905 aus dem gesamten zur Verfügung stehenden Material alle beobachteten Complexe in drei Hauptabteilungen des Krystallreiches abgetrennt wurden und zunächst für die dem hypohexagonalen Typus angehörenden Krystalle specielle Tabellen fertiggestellt wurden, damals noch in der Anzạhl von etwa 800 Substanzen, und zugleich die erste Prüfung derselben zustande $\mathrm{kam}$, wozu $\mathrm{Hr}$. Demjanow freundlichst beigetragen hatte, indem derselbe mir zu dieser Prüfung an der Hand jener Tabellen eine Reihe von Substanzen übergab; und alle diese wenigen Substanzen wurden richtig bestimmt, wobei sich erwies, daß für diese Bestimmungen ein Zeitaufwand von $2-3$ Stunden hinreichend ist.

Die neuen, vollständigeren Tabellen, welche etwa zehntausend Substanzen und sämtliche zur Verfügung des Verfs. stehenden Beschreibungen der Krystalle umfassen, wurden im Sommer 1910 fertiggestellt, und die erste Anwendung derselben geschah am 25. September desselben Jahres an einem wunderschön ausgebildeten Krystalle von sehr bedeutender Größe, einem Laboratoriumsproducte, welches in der technischen Abteilung des Museums des Berginstituts sich ohne jede Etikette vorfand. Dann folgte eine längere Versuchsreihe an Krystallen, welche liebenswürdigerweise zu diesem Zwecke von verschiedenen Collegen zugesandt wurden; davon wird etwas näher im Schlußteile dieser Arbeit berichtet. Diese Versuchsreihe dauerte während des acad. Jahres 1910-1911.

Diese längere Versuchsreihe hat gezeigt, daß sich im großen und ganzen an den gemessenen Krystallen, welche wir insofern als gut ausgebildet erkennen, als sie sich messungsfähig erweisen, doch ziemlich bedeutende Abweichungen von den angegebenen Winkelgrößen erkennen lassen, und gerade darin bestand die größere Schwierigkeit bei der Bestimmung. Für die meisten ist dies natürlich nicht der Fall, für manche aber ließ sich die Übereinstimmung bis auf wenige Minuten constatieren; solche gehören somit

1) Gerade bei dieser Bestimmung entstanden für viele Mineralien specielle Schwierigkeiten, indem es sich herausstellte, daß in der Mehrzahl der Fälle nur sehr wenige Formen vertreten sind, und es kam vor, da $B$ gerade diesen wichtigsten Formen in der angenommenen Aufstellung eine geringere Bedeutung zukommt. Auf diese Weise ließ sich der Begriff der wirklichen Reihenfolge der Formen nach ihrer Wichtigkeit entwickeln, und der Verf. mußte von Neuem eine Reihe von Mineralien untersuchen, speciell um daraus diese Reihenfolge festzustellen.

Groth, Zeitschrift f. Krystallogr. L. 
zu den am leichtesten bestimmbaren, da für dieselben unmittelbar nach den für die Tabellen angenommenen Coordinaten die Punkte aufgefunden wurden; für die übrigen kam aber nicht ein einziger, sondern auch die nächst liegenden Punkte zur Berücksichtigung.

In $\mathrm{Z}$ weifelfällen mußten, wie oben bemerkt, auch die anderen individuellen Eigenschaften der betreffenden Substanzen herbeigezogen werden. Aber man kann überhaupt sagen, daß es stets nützlich ist, eine möglichst große Anzahl dieser Eigenschaften in Betracht zu ziehen, weil deren Prüfung einen ganz unbedeutenden Zeitverlust erfordert.

Jetzt steht mir bevor, allein die krystallographischen Verfahren darzulegen, welche nötig sind, um die zur Bestimmung dienenden Tabellen auf rechte Weise zu gebrauchen.

Als die Methode der krystallographischen Messung empfiehlt sich natürlich diejenige einfachste und rascheste Methode mit Hilfe des speciellen Universalgoniometers, deren besondere Vorzüge ich noch im Jahre 1889 in specieller Mitteilung der K. St. Petersburger Mineralogischen Gesellschaft hervorhob ${ }^{1}$ ).

Als Resultat dieser Krystallmessung entsteht das Diagramm in gnomostereographischer Projection, aus welcher auch ein weniger geübtes Auge fast direct den Typus, die Syngonieart und oft auch die Hauptstructurart abliest. Um daraus die bestimmenden Zahlen zu ermitteln, muß eine Aufstellung vorausgesetzt und nach den weiter zu erörternden Regeln die eindeutigen Flächensymbole aufgestellt werden, und dann ist der ganze Complex in bestimmte Orienlierung im Diagramm zu stellen.

In anderen Fällen kann sogar ein sehr geübtes Auge nicht direct die richtige Aufstellung ersehen; je nach den dazukommenden Voraussetzungen entstehen dann besondere Prüfungen.

Der richtigste Weg, das endgültige Resultat zu gewinnen, ist der der besonderen Prüfung jeder gemachten Voraussetzung; dann läßt sich das endgültige Resultat, als Resultat der oben erläuterten Rechnungen, von selbst erhalten.

Dieser umständlichere Weg bei der Ausführung dér krystallochemischen Analyse ist aber nicht zu empfehlen, schon aus dem Grunde, weil es nicht in allen Fällen möglich war, bei der Zusammenstellung der Tabellen die richtige Aufstellung zugrunde zu legen. Wie oben erklärt wurde, ist dazu die Erfüllung bestimmter Anforderungen an die krystallographische Beschreibung nötig, und diese ist durchaus nicht in allen Fällen gegeben.

Wie die jetzige Erfahrung lehrt, kann die Bestimmung viel kürzer geschehen, wenn man zuerst die subjectiv wahrscheinlichste Aufstellung gelten läßt, darauf die Ermittlung der bestimmenden Zahlen gründet, und

1) Verhandlungen dieser Gesellschaft 27, 458. 
nur dann, wenn es sich zeigt, daß der gegebenen Annahme keine in den Tabellen gegebene Substanz entspricht, $\mathrm{zu}$ einer anderen zulässigen Aufstellung übergeht. Die Bestimmung kann sogar dann statthaben, wenn in den Tabellen selbst eine nicht richtige Aufstellung zugrunde gelegt worden ist.

Jetzt gehe ich über zu der Darlegung der Operationen der Orientierung des Complexes auf dem Diagramm, der Aufsuchung der eindeutigen Flächensymbole, der Ermittlung der bestimmenden Zahlen und folglich der Zusammensetzung des Complexsymbols und endlich der Verification der vorausgesetzten Aufstellung.

Da diese Operationen für verschiedene Modalitäten etwas verschiedenartig ausfallen, so will ich diese Operationen an einer größeren Reihe von Beispielen veranschaulichen. Wie aber schon in meiner erwähnten Grundarbeit dargetan wurde, gibt es eine so kolossale Anzahl von Modalitäten, daß es unmöglich erscheint, für jede von ihnen Beispiele zu betrachten, ich begnüge mich daher mit einer solchen Auswabl derselben, daß daraus ganz klar hervorgeht, wie man auch in allen übrigen Fällen zu verfahren hat.

Vor allen anderen ziehe ich aber als Beispiele solche Substanzen zu betrachten vor, welche schon zu Objecten der krystallochemischen Analyse gedient hatten und folglich einer gründlichen Verification unterzogen wurden, und für welche es außer Zweifel steht, daß sie bestimmungsfähig sind.

Unter diesen Substanzen sind aber solche vertreten, welche den ideellen Complexen entsprechen, und für welche keine besondere Erläuterung nötig ist; unter ihnen sind ferner einige Modalitäten mehrere Male wiederholt vertreten. Aus diesem Grunde war ich genötigt solchen Beispielen noch eine Anzahl anderer hinzuzufügen, um das gesamte Bild der Bestimmungsoperationen möglichst vielseitig zu beleuchten.

Das gesamte krystallographische Material außer den ideellen, unter ihnen auch speciell den kubischen Krystallen, läßt sich in folgende Hauptabteilungen gliedern.

\section{Die Krystalle des kubischen Typus.}

1. Tetragonaloïde. Hauptstructurart.

a) Hexaëdrische, b) Oktaëdrische, c) Dodekaëdrische. Syngonieart
für sämtliche drei
Structurarten: $\left\{\begin{array}{l}\text { Rhombisch } \\ \text { Monoklin. } \\ \text { Triklin. }\end{array}\right.$
2. Hexagonaloïde.

(Trigonaloïde.)

Hier sind dieselben Abteilungen a), b) und c) zu unterscheiden.

$\left\{\begin{array}{l}\text { Monoklin. } \\ \text { Triklin. }\end{array}\right.$ 
II. Die Krystalle des hypohexagonalen Typus. (Hierzu gehört die prismatische Hauptstructurart allein.)

$$
\text { Syngonieart: }\left\{\begin{array}{l}
\text { Rhombisch. } \\
\text { Monoklin. } \\
\text { Triklin. }
\end{array}\right.
$$

Von den ideellen Krystallen sind nur diejenigen des hypohexagonalen Typus und dabei der trigonalen Hyposyngonie, einer kleinen Erörterung bedürftig.

Unter ihnen sind nämlich die Modalitäten zu unterscheiden, in welchen 1) eine und folglich jede Symmetrieebene zu den respectiven drei Flächen $\{0110\}$ senkrecht steht, und 2) wenn eine und folglich jede Symmetrieebene denselben Flächen parallel ist; wenn zweizählige Symmetrieaxen vorhanden sind, so sind sie im zweiten Falle zu den respectiven Flächen senkrecht, im ersten aber parallel.

In dem ersten Falle wird dem Complexsymbol +, im letzten - hinzugefügt.

Z. B. dem Quarz, wie wir schon gesehen haben, kommt das Zeichen + zu.

Der zweite Fall ist sehr selten vertreten; zu ihm gehört z. B. die hexagonale Modification von Cäsiumchromat; dessen Complexsymbol ist $-\underset{30}{6} 0^{0} 56^{\prime \prime}$ Da diese Substanz ditrigonalskalenoëdrisch ist, so weist das Symbol darauf hin, daß die Symmetrieebenen den Flächen von $\{0110\}$ parallel, die zweizähligen Symmetrieaxen aber dazu senkrecht stehen.

Unter den fünf Symmetriearten der trigonalen Hyposyngonie, und zwar 1) der trigonalpyramidalen, 2) der rhomboëdrischen, 3) der ditrigonalpyramidalen, 4) der trapezoëdrischen und 5) der ditrigonalskalenoëdrischen, sind in den ersten beiden überhaupt keine Symmetrieebenen und keine zweizähligen Symmetrieaxen vertreten. Demgemäß sind für diese beiden dem Complexsymbol die beiden Zeichen \pm zuzufügen.

Dies ist z. B. für Guajol ${ }^{1}$ ) der Fall, dessen Complexsymbol $\pm 32^{6} 24^{\prime}$ u. a. die Zugehörigkeit zu einer dieser beiden Symmetriearten ausdrücken soll, da in der Tat seine Symmetrieart die trigonalpyramidale ist, obgleich die Zugehörigkeit zum hypohexagonalen Typus sehr scharf durch seine Combination zum Ausdruck kommt $(1000,0110,1110,1110)$.

Ich lasse die angeführten Beispiele in der oben angegebenen Anordnung folgen ${ }^{2}$, beginne also mit dem kubischen Typus.

1) z. B. in v. Groth's Chem. Kryst. 3, 763.

2) Vergl. Taf. XI, auf welcher die betr. Diagramme mit der Nummer und dem Complexsymbol jedes Beispiels bezeichnet sind. 


\section{Krystalle des kubischen Typus.}

\section{Tetragonaloïde.}

a. Hexaëdrische Hauptstructurart.

\section{Rhombische Syngonie.}

1. Beispiel. Natriumkaliumtartrat-Tetrahydrat (Seignette-Salz)

$$
\mathrm{C}_{4} \mathrm{H}_{4} \mathrm{O}_{6} \mathrm{KNa} .4 \mathrm{H}_{2} \mathrm{O} \text {. }
$$

(Die Krystalle wurden zur Bestimmung zweimal zugesandt und zwar von den Herren Duparc und Barker.)

Dieses erste Beispiel ist zugleich ein besonders interessantes, da hier nur die Hauptzone und die Form $\{001\}$ sich durch Constanz des Erscheinens auszeichnen. Alle schiefen Flächen sind dagegen sehr klein, schlecht ausgebildet und sehr unbeständig in ihrem Erscheinen. In beiden Zusendungen prägte sich diese Unbeständigkeit dadurch aus, daß in einer davon öfters einige, in der anderen auch andere schiefe Flächen auftreten.

Trotz dieser Unbeständigkeit muß diese Substanz den krystallographisch leicht bestimmbaren zugerechnet werden, und zwar aus folgendem Grunde:

Aus den unten angegebenen Größen der reticulären Dichtigkeiten ersieht man deutlich, daß für diesen Complex nur einige Flächen der Hauptzone und $\{001\}$ zu berücksichtigen sind; vom theoretischen Standpunkte aus wäre solche Unbeständigkeit von vornherein zu erwarten. Die richtige Aufstellung muß aber eine solche sein, daß weder wichtigste Formen der Hauptzone noch $\{001\}$ auf zu vernachlässigende zu beziehen wären. Dem entspricht aber nur ein gewisses Intervall in der Reihengröße der bestimmenden Hauptzahl.

Die gut entwickelte Hauptzone ist entschieden eine tetragonaloide und ihre Flächen erhalten sofort die Indices $\{100\},\{010\},\{110\},\{210\}$ und $\{120\}$, und gerade diese Formen sind durch Beständigkeit ausgezeichnet.

Wenn, wie es für eine Zusendung wirklich der Fall war, die Form \{111\} der richtigen (d. h. in dem beigegebenen Diagramm aufgezeichneten) Aufstellung vollständig abwesend war, dagegen (obgleich sehr unbeständig und unvollzählig) nur die Formen $\{211\}$ und $\{221\}$ erschienen, so bätte man meinen können, daß gerade $\{221\}$ durch die Indices $\{111\}$ zu be$4 \mathrm{~h}$

zeichnen wäre; hätten wir für den Complex das Symbol 58· ermittelt (dabei 2

100 der richtigen Aufstellung als 001 aufgefaßt), so würde die Hauptzone sehr schwach vertreten sein, und gerade die beständigsten Formen der richtigen Hauptzone hätten ihre Bedeutung verloren.

Bei der erwähnten unrichtigen Aufstellung hätten wir sogar für $\{201\}$, welches dann die Indices $\{101\}$ erhielte, etwas größere reticuläre Dichtigkeit 
gehabt, als für $\{110\}$, welches dann die Indices $\{011\}$ erhielte, was im grellen Widerspruch mit den wirklich beobachteten Verhältnissen steht. In der Summe hätten wir somit einen viel geringeren Aufstellungswert erhalten.

Bei der jetzt als die richtige angenommenen Aufstellung erhalten wir $4 \mathrm{~h}$

als Complexsymbol 34, und auf Grund dessen läßt sich folgende Tabelle b

zusammenfassen:

$\begin{array}{lccccccc}\text { Reihe der Dichtigk. } & 1 & 2 & 3,4 & 5 & 6,7 & 8,9 & 10,11 \\ \text { Indices } & 100 & 010 & 110 & 001 & 210 & 101 & 011 \\ \text { Flächendicht. } & 22,20 & 15,40 & 8,80 & 4,00 & 3,86 & 3,39 & 3,18\end{array}$

Reihe der Dichtigk. 12,13 14-17 - $\quad-\quad-\quad-$ Indices

Flächendicht.

\begin{tabular}{rrrrrrr}
120 & 111 & 310 & 121 & 130 & 201 & 221 \\
\hline 2,82 & 2,76 & 1,96 & 1,65 & 1,56 & 0,57 & 0,33
\end{tabular}

In dem Complexsymbol bezeichnet die obere Zahl die Zugehörigkeit zu den tetragonaloïden (Ziffer 4) Complexen hexaëdrischer (Buchstabe b) Hauptstructurart. Die Hauptzahl 34 drückt die Winkelgröße (001):(111) aus und die untere Zahl (5) die Abweichungsgröße des Winkels (100):(110) von der Limitgröße $45^{\circ}$.

Die nähere Betrachtung der Tabelle lehrt uns einen sehr seltenen Fall kennen, in welchem eine so große Anzahl der theoretisch wichtigsten Flächen vertreten ist und wenigstens zehn erste Flächen sich durch relative Constanz des Erscheinens auszeichnen.

Wenn wir, wie gewöhnlich, nur die ersten fünf Flächen berücksichtigen, so kann man annähernd sagen, daß die Anzahl des stetigen Auftretens der Formen in der Reihenfolge ihrer theoretischen Wichtigkeit sogar etwas geringer ist als der Fälle, wo dies nicht stattfindet. Natürlich steht dieses Verhältnis in enger Verbindung mit der Art des Complexes selbst; für die extrem positiven Complexe kann man sogar sagen, daß dies niemals der Fall ist und die Anzahl der beständigen Formen fast lediglich sich auf die dominierende Tafel-, resp. blätterige Fläche reduciert.

Das nähere Studium solcher Verhältnisse ist natürlich Sache der künftigen Zeit. Jetzt können wir nur wenige erläuternde Bemerkungen hervorheben.

Solche Flächen, deren Dichtigkeit z. B. sechs-, sieben-, ...mal kleiner ist, als die der ersten Form, gebören überbaupt den unbeständigen und zu vernachlässigenden Formen an, und in diesem seltenen Falle haben wir fast zehn erste Flächen als constante vertreten. Für solchen Fall gilt besonders die Behauptung, daß die Formenentwicklung eine ideelle, d. $\mathbf{h}$. der betreffende Aufstellungswert gleich 1, der größtmögliche, ist.

Was die Flächensymbole anbetrifft, so wird stets $\{100\}$ derjenigen (von 
zwei) Form zuerteilt, für welche die Winkelgrüße mit $\{110\}$ bedeutender ist, als für $(010):(110)$.

Unter dieser Bedingung wird die reticuläre Dichtigkeit von $\{100\}$ stets grüßer als die von $\{010\},\{101\}$ größer als $\{011\},\{210\}$ größer als $\{120\}$, \{211\} größer als $\{121\}$ usw.; überhaupt sind die Dichtigkeiten für alle Formen, deren Pole in den Grenzen des sphärischen Dreiecks 100.110.001 liegen, größer, als die respectiven Formen für das Dreieck 010.110.001.

Diese Verhältnisse sind nur die besonderen Äußerungen des zweiten Gesetzes der Formenentwicklung, welches schon längst erkannt wurde ${ }^{1}$ ). Von diesem Gesetze werden weiter noch vielfache Verwendungen gemacht.

Der Vergleich mit den Resultaten des Studiums derselben Substanz durch andere Autoren, welche z. B. in v. Groth's Chemischer Krystallographie 3, 332 zusammengestellt worden sind, zeigt, daß sogar bei dem Studium einer kleineren Anzahl von Krystallen, für deren Analyse eine größere Anzahl von Formen angetroffen wurde, als früher erwähnt sind. Als neu wurden die Formen $\{310\},\{130\},\{221\}$ beobachtet. Aber, wie man aus der beigegebenen Tabelle ersieht, gehören alle diese Formen gerade den zu vernachlässigenden an und spielen fast keine merkliche Rolle in dem Complexe; sie erscheinen sporadisch, sind sehr klein, undeutlich entwickelt und stets unvollzählig ${ }^{2}$ ).

Als optisch active Substanz muß dieselbe der rhombisch-sphenoëdrischen Classe angehören; folglich sind solche Formen wie $\{111\}$ und $\{T \mid 1\}$ als verschiedene auseinander zu halten.

Aber in den verfaßten Tabellen ist dies fast unberücksichtigt geblieben, und zwar aus dem jetzt verständlichen Grunde, daß überhaupt nur sehr wenige Formen sich durch Beständigkeit auszeichnen. Wäre z. B. eine der Formen $\{111\}$ resp. $\{111\}$ nicht erschienen, so bleibt dies für die $\mathrm{Be}-$ stimmung, folglich für die Abfasșung der Tabellen fast ohne Belang; überhaupt gehören diese Formen den zu vernachlässigenden an und können außer Betracht bleiben.

Vom structurtheoretischen Grunde aus erscheint es unmöglich, zwischen diesen Formen in bezug auf die Wichtigkeit einen Unterschied zu machen, da den beiden genau die gleiche reticuläre Dichtigkeit zukommt. Wir wissen aber, daß für das Krystallisationsverfahren diese Dichtigkeit nicht der allein wirkende Factor ist, und dann wird es begreiflich, daß in der Tat ein Unterschied in der Entwicklung statthaben kann.

Im großen und ganzen stimmt die Erfahrung mit der theoretischen Folgerung sehr gut überein, da überhaupt unvollzählig nur die Formen

1) Und gegenwärtig schon in den fortgeschritteneren Elementarlehrbüchern der Krystallographie dargelegt wird.

2) Als ganz zufällige Formen, durch einzelne Flächen angedeutet, erschienen noch einige andere, aber sie sind nicht einmal erwähnenswert. 
von untergeordneter Bedeutung erscheinen. Aber, da in einigen Fällen sogar die wichtigsten Formen nicht zur Erscheinung kommen können, so künnen auch Fälle auftreten (und wirklich wurden solche gefunden), in welchen sogar die wichtigsten Complexflächen unvollzählig auftreten.

2. Beispiel. d- und l-Camphersäureanhydrid $C_{g} H_{14}<C O>O$.

(Diese Substanz ließ sich in der Zusendung von Herrn Barker bestimmen.)

Für diese Substanz ist das Complexsymbol $\begin{gathered}4 \mathrm{~h} \\ 49\end{gathered}$ -3 .

Wir haben hier einen Fall besonderer Modalität vor uns, welche zu den sogenannten Modalitäten zweiter Art gehört, und für welche in dem Symbol der unteren Zahl (welcher übrigens dieselbe Bedeutung zukommt, wie in allen übrigen Fällen) das Zeichen - beigegeben wird. Dieses Zeichen bedeutet, daB im rhombischen Krystall nicht der Winkel (100): (040), sondern der Winkel $(110):\left(1 T_{0}\right)$ genau gleich $90^{\circ}$ ist. Natürlich sind in diesem Falle die Winkel $(100):(110)$ und $(010):(110)$ die gleichen, aber der Winkel $(100):(110) \mathrm{muB}$ größer sein als $45^{\circ}$, folglich größer als $(100):(1 \overline{1} 0)$

Unter dieser Bedingung kommt der Hauptzahl (hier 49) als der Winkelgröße (001):(111) eine ganz bestimmte Bedeutung zu (für 001:1T1 haben wir z. B. in diesem Falle 520, wie dies durch die punktierte Linie angedeutet worden ist). Auf Grund des oben erwähnten zweiten Gesetzes der Formenentwicklung kann man schließen, daß den Formen des sphärischen Dreiecks 100.010.001 stets größere reticuläre Dichtigkeit zukommt, als den respectiven Formen des Dreiecks 100.07̄0.001. In diesem Falle ist z. B. die reticuläre Dichtigkeit für (111) gleich 1,72 und für (1T1) nur 1,52.

Auf Grund der Beobachtung ist folgende Tabelle zusammengefaßt:

$\begin{array}{ccccc}1,2 & 3 & 4 & 6-9 & - \\ 100 & 001 & 110 & 101 & 1 \overline{1} 0 \\ 5,28 & 4,00 & 3,02 & 2,29 & 2,43\end{array}$

Aus dieser Tabelle ersieht man, daß die Formenentwicklung in diesem Falle schon keine ideelle ist, da die Form $(1 \bar{T} 0)$, welcher der fünfte Platz im Complexe gehört, abwesend ist. Dies bezieht sich auf die Individualität des Complexes, ebenso wie die relative Seltenheit des Erscheinens der Form $\{001\}$, welche dabei unvollzählig (also durch eine einzige Fläche vertreten) zutage trat.

Für die rechnerische Verification der Aufstellung erhalten wir für $R$ die Summe $2 \times 5,28+4,00+3,02+4 \times 2,29=26,74$ " $J$ " $2 \times 5,28+4,00+3,02+2,43+3 \times 2,29=26,88$.

Also $\frac{R}{J}=\frac{2674}{2688}=0,99$. 
Nun ist aber diese Zahl der Einheit so nahe stehend, daß man allerdings hätte sagen können, die Formentwicklung sei auch in diesem Falle fast ideell, wenn nicht der Umstand vorläge, daß die Form $\{001\}$ eine seltene und fast verschwindende ist.

Der Vergleich mit den Resultaten von Herrn Grünling u. $A$., welche in Chem. Kryst. 3, 731 wiedergegeben sind, zeigt, daß die Form $\{001\}$ sogar nicht angegeben wurde.

\section{Monokline Syngonie.}

3، Beispiel. Diphenyl-methyl-methylenazid $\underset{\mathrm{CH}_{3}}{\mathrm{CH}_{6} \mathrm{H}_{5}}>\mathrm{C}: \mathrm{N} . \mathrm{N}: \mathrm{C}_{<} \mathrm{C}_{6} \mathrm{CH}_{3}$.

(Aus der Zusendung von Herrn Barker bestimmt.)

Das Diagramm stützt sich auf die liebenswürdig von Herrn Barker privat mitgeteilten, damals noch unveröffentlichten Messungen von Herrn Drugman ${ }^{1}$.

Diesem Complex entspricht das Symbol $\begin{gathered}4 \mathrm{~h} ;+13 \\ 60 \\ 3\end{gathered}$

Im Vergleich mit früheren, sehen wir hier noch der oberen Zahl +13. beigegeben. Sie bezeichnet die Größe der monoklinen Verschiebung (welche nötig ist, um den Complex in einen rhombischen zu verwandeln), und dabei soll speciell das Zeichen + darauf hinweisen, daß der Symmetrieebene des Complexes die Fläche (010) parallel ist.

Aus dem beigegebenen Diagramm ersieht man direct die Abweichung der Formenentwicklung von der ideellen, da auf Grund des zweiten Gesetzes die Form $\{101\}$ größere Dichtigkeit besitzen muß als $\{101\}$, und $\{101\}$ größere als $\{011\}$, und nur die letztere in dem Complex wirklich vertreten ist.

Auf Grund dieses Gesetzes müssen den Formen mit negativen ersten Indices (also sämtlichen Formen des größeren Teiles der Hemisphäre) größere Dichtigkeiten zukommen, als den respectiven Formen mit positiven ersten Indices. Was das Verhältnis von $\{101\}$ zu $\{011\}$ anbetrifft, so geht das Gesagte klar davon aus, daß es bei allen Lagen des Poles von $\{001\}$ richtig sein muß, und die Richtigkeit desselben für den Fall, daß dieser Pol in den Projectionsmittelpunkt kommt (nach der erfolgten monoklinen Verschiebung), ist schon oben erklärt worden.

Inwiefern diese wichtige individuelle Besonderheit des Complexes in der Verminderung des Aufstellungswertes sich kundgibt, ersieht man aus der folgenden Tabelle:

1) Bevor die systematische Praxis zu der krystallochemischen Analyse führte, hat Herr Barker die Diagramme von einigen Dutzenden neu untersuchter Krystalle zugesandt, damit in der folgenden Zusendung u. a. auch diese Krystalle bestimmt werden konnten. 


\begin{tabular}{ccccccccc}
1 & 2 & 3 & 6,7 & 12,13 & - & - & - & - \\
001 & 100 & 010 & 011 & $111 ;$ & $\overline{101}$ & 101 & 110 & 111 \\
\hline 3,78 & 3,02 & 2,27 & 1,42 & 0,$88 ;$ & 2,18 & 1,73 & 1,33 & 1,12
\end{tabular}

Daraus ermitteln wir die Werte

$$
\text { für } \begin{aligned}
R=3,78+3,02+2,27+2 \times 1,42=11,91 \\
\searrow \quad J=3,78+3,02+2,27+2,18+1,73=12,98
\end{aligned}
$$

Also $\frac{R}{J}=\frac{1191}{1298}=0,92$.

Da der Complex monoklin ist, so ist diese Zahl (bei dem Vergleiche mit anderen zulässigen Aufstellungen) noch mit dem Cos (13) zu multiplicieren.

Dieser Wert ist durchaus größer, als der durchschnittliche Wert der Aufstellung überhaupt.

Ich erlaube mir noch einige Worte in bezug auf Bestimmung der Dichtigkeitsgrößen der monoklinen Krystalle überhaupt beizufügen.

Die Dichtigkeit aller schief stehenden Flächen, hier wie in allen anderen Fällen überhaupt (die triklinen Krystalle nicht ausgenommen), wird direct durch die Ablesung des centralen Winkels ihrer Pole bestimmt.

Führen wir aber die monokline Verschiebung aus, deren Ebene die Ebene der Zeichnung ist und deren Richtung und Größe durch die Lage des Poles von (001) gegeben wird, indem dieser Pol nach der erfolgten Verschiebung in die Lage des Mittelpunktes kommt, so erhalten wir gerade für die sämtlichen schiefen Flächen andere Größen für ihre Centralwinkel. Wir haben jetzt schon mit einem rhombischen Complex zu tun und können nach den bekannten Regeln auch die Dichtigkeitsgrößen für die Flächen der Hauptzone bestimmen, deren Pole auf dem Projectionskreise verbleiben. Denken wir uns dann die gerade entgegengesetzte Verschiebung ausgeführt, so ändern sich die Dichtigkeitsgrüßen aller schief stehenden Flächen, nicht aber die der Flächen der Hauptzone. Daraus folgt, daß durch diese Verschiebung möglich gemacht wird, gerade die Werte für die Flächen der Hauptzone zu bestimmen. Dazu gehört also eine bestimmte Verschiebung.

Auf der Zeichnung ist der Weg der Bewegung des Poles von (111) angegeben, welchen er während der Verschiebung durchläuft; kommt derselbe endlich in die Lage $a$ an dem Durchmesser von (110), so dient gerade die Centralwinkeldistanz dieses Poles zur Bestimmung der Dichtigkeitsgröße von $(110)$.

Für monokline Krystalle ist aber die Ausführung dieser Verschiebung für die Dichtigkeitsbestimmung durchaus nicht notwendig. Man kann den Projektionsmittelpunkt durch den Pol von (010) ersetzen, hat dann aber die Winkel aller übrigen Pole von diesem Pole abzulesen. Auf diese Weise erhält man natürlich andere absolute Zahlen (und zwar größere, weil jetzt für 010 sich die Zahl 4,00 ergibt, anstatt 2,27), aber das Verhältnis der 
respectiven Zahlen bleibt dasselbe, sodaß das Resultat identisch wird. Um z. B. die Dichtigkeit von (101) zu bestimmen, muß man jetzt die Winkeldistanz von dem Pol von (010) bis zum Pol von (111) (und keineswegs von a) ablesen; für (T01) wäre dann die Winkeldistanz von (010) bis (T11) abzulesen.

4. Beispiel. Natriumlanthannitrat-Trihydrat $\left.\left(\mathrm{NO}_{3}\right)_{10} \mathrm{La}_{2} \mathrm{Na}_{4} \cdot 3 \mathrm{H}_{2} \mathrm{O}\right)$.

Diese von Herrn W y rou b off krystallographisch beschriebene Substanz ${ }^{1}$ ) stellt eine besondere hierher gehörende Modalität dar, deren Complex durch das Symbol $\begin{gathered}4 \mathrm{~h} ;-\frac{1}{2} \\ 28 \cdot\end{gathered}$

Die Verschiebungsgröße mißt in diesem Falle nur ungefähr $\frac{1}{2}{ }^{0}$, der Complex kommt also dem rhombischen sehr nahe; was aber das Zeichen der oberen Zahl anbetrifft, so soll dies ausdrücken, daß jetzt die Flächen $\{100\}$ der Symmetrieebene des Complexes parallel sind.

Die untere Zahl 0 soll ausdrücken, daß der Winkel $(100):(110)$, also auch (010):(110) mit graphischer Genauigkeit gleich 4:0 ist; da aber in Wirklichkeit doch eine Abweichung von einigen Minuten vorhanden ist, so kommt der Pol von (100) in die auf dem Diagramm angegebene Lage. Es kann aber sein, daß die Genauigkeit der mittleren Zahlen die Größe der Abweichung nicht übersteigt, und falls es richtiger wäre, daß der Pol von (110) die besondere Lage (von 450) überschritten hätte, so wäre anstatt (100) (010) zu setzen, also in der oberen Zahl + anstatt - Allerdings ist dies eine Übergangsmodalität (nicht eine typische).

Um den aufgestellten Anforderungen zu genügen, muß eine Transformation der Indices vorgenommen werden, welche durch die beigegebene Determinante ihren Ausdruck findet:

\begin{tabular}{c|ccccccccc}
020 & 2 & 1 & 9 & 5,6 & - & 11,12 & - & - & - \\
100 & 100 & 010 & 001 & 110 & 101 & $012 ;$ & - & - & - \\
\cline { 2 - 11 } 001 & 010 & 100 & 001 & 210 & 011 & $101 ;$ & 110 & 120 & 071 \\
& 27,16 & 27,16 & 4,00 & 4,92 & 3,46 & 3,49 & 13,56 & 4,92 & 3,51
\end{tabular}

Aus dieser Tabelle ersehen wir die schon ziemlich große Abweichung von der ideellen Formenentwicklung, da die Flächen $\{110\}$ mit der Dichtigkeitsgröße 13,56, welchen der dritte und der vierte Platz in dem Complexe zukommt, ebenso wie die Flächen $\{120\}$ mit der Dichtigkeitsgröße 4,92 abwesend sind; auch fehlt $\{0 \bar{T} 1\}$.

Ziehen wir, wie gewöhnlich, nur fünf Flächen in Betracht, so erhalten wir

1) Bull. d. la Soc. franç. de minér. 1907, 30. Refer. in dieser Zeitschr. 46, 504. 


$$
\begin{array}{ll} 
& \text { für } R=2 \times 27,16+2 \times 4,92+4,00=68,16 \\
» \quad J=2 \times 27,16+2 \times 13,56+4,92=86,36 . \\
\text { Also } \quad \frac{R}{J}=\mathbf{0 , 8 0 .}
\end{array}
$$

5. Beispiel. 1.3-Diphenyl-5-Methylpyrazol

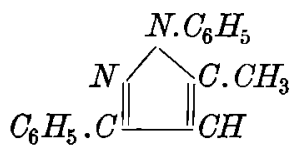

Dieser von Herrn Winkle $\mathbf{r}^{1}$ ) krystallographisch beschriebenen Substanz $4 \mathrm{~h} ; \frac{1}{2}$

kommt das Complexsymbol 26 zu. Dies bedeutet, daß hier schon die 4 .

Flächen $\{001\}$ der Symmetrieebene des Complexes parallel sind, wie auch aus dem beigegebenen Diagramm direct ersichtlich ist; dies ist nämlich dadurch ausgedrückt, daß die obere Zahl obne jedes Zeichen steht.

Auch jetzt sind die vom Autor gegebenen Indices, den allgemein auf-

\begin{tabular}{|c|c|c|c|c|c|c|c|c|c|c|}
\hline \multirow{4}{*}{\begin{tabular}{lll|}
0 & 0 & 1 \\
1 & 0 & 0 \\
0 & 1 & 0
\end{tabular} \mid} & 1 & 2 & 10,11 & 3 & 4 & - & - & - & $\longrightarrow$ & - \\
\hline & 001 & 100 & 110 & $\bar{T} 01$ & $101 ;$ & - & - & - & - & - \\
\hline & 100 & 010 & 011 & $1 \bar{T} 0$ & $110 ;$ & 001 & 210 & $2 \bar{T} 0$ & 120 & $1 \overline{2} 0$ \\
\hline & 37,9 & 27,2 & 3,5 & 16,8 & 16,0 & 4,0 & 7,0 & 7,4 & 5,6 & 5,8 \\
\hline
\end{tabular}
gestellten Anforderungen gemäß, etwas abzuändern, was stets durch die respective Determinante klargestellt wird.

In diesem außerordentlich stark negativen Complex dominieren die Dichtigkeitsgrößen der Flächen der Hauptzone in solchem Grade, daß der ersten, dieser Zone nicht zugehörenden Form $\{001\}$ erst der neunte Platz zukommt; dieselbe muß sich also unter den zu vernachlässigenden Formen befinden und gelangt wirklich keinmal zur Beobachtung.

Als auf die besondere individuelle Eigenschaft dieses Complexes ist auf die verhältnismäßig große Entwicklung der Form $\{011\}$ hinzuweisen.

Jetzt erhalten wir für $R=37,9+27,2+16,8+16,0+3,5=101,4$ und für $J=37,9+27,2+16,8+16,0+7,4=105,3$.

Also $\frac{R}{J}=0,96$.

Wieder haben wir einen großen Aufstellungswert erhalten.

Weiter lasse ich zwei Beispiele folgen, welche sich auf eine und dieselbe Modalität beziehen; beide wurden bei der Prüfung leicht bestimmt.

6. Beispiel. Baryumchlorid-Dihydrat $\mathrm{BaCl}_{2}, 2 \mathrm{H}_{2} \mathrm{O}$.

(Diese Substanz war in der Zusendung von Herrn v. Groth enthalten.)

$$
\text { 4. } \mathrm{h} ; 1
$$

Das Complexsymbol für dieselbe ist 72 .

1) Diese Zeitschr. 24, 335, 
Die Bedeutung aller in dem Symbol enthaltenen Zahlen ist jetzt aus den obigen Erläuterungen klar geworden.

Für diesen Fall gilt folgende Tabelle:

\begin{tabular}{|c|c|c|c|c|c|c|c|c|c|}
\hline \multirow{3}{*}{$\begin{array}{l}10 \bar{\pi} \\
101 \\
020\end{array} \mid$} & 1 & 3 & 6,7 & 2 & 4,5 & - & - & - & - \\
\hline & 010 & 101 & 111 & $\overline{1} 01$ & $T 11$ & 110 & 120 & 011 & 021 \\
\hline & 001 & 010 & 011 & 700 & $\overline{1} 01$ & 112 & 114 & $T 12$ & $\overline{T 14}$ \\
\hline & 4,00 & 0,79 & 0,66 & 0,83 & 0,79 & - & - & - & - \\
\hline
\end{tabular}

Dieser Complex ist auf die Modalitäten zweiter Art bezogen, weil in diesem Falle der Winkel $(110):(1 \bar{T} 0)$ dem rechten näher steht, als der Winkel (100):(010); natürlich ist für die rhombischen Krystalle der eine dieser Winkel genau ein rechter; für die monokline ist dies für keinen der beiden Winkel der Fall; somit sind die Modalitäten zweiter Art der monoklinen Krystalle nur Annäherungen (in verschiedenem Grade) an solche der rhombischen Krystalle.

Dieser Complex ist im Gegensatz zu dem vorigen stark positiv. Wie dieser Umstand auf die Reihenfolge der Dichtigkeitsgrößen einwirkt, ersieht man aus dem Vergleiche dieser beiden Tabellen, ebenso wie darin, daß im vorigen Falle die Form $\{001\}$ auf die zu vernachlässigenden bezogen wurde und wirklich keinmal zur Beobachtung kam, während sie sich hier vor allen übrigen Flächen durch besondere Wichtigkeit und Entwicklung auszeichnet.

Aus der Tabelle ersehen wir zugleich, daß die Formenentwicklung hier die ideelle ist, insofern alle Flächen, welchen ein niedrigerer Platz als der siebente zukommt, zu vernachlässigen sind; während für die erste Form die Dichtigkeitsgröße durch 4,00 ausgedrückt wird, ist die respective Zahl für die siebente Fläche nur 0,66 .

7. Beispiel. 1-Phenyl-2-Äthyl-3 l-Bornyl-Imidoxanthid von der Structur etwa $C_{6} H_{5} . C: N \cdot C_{2} H_{5}$

$\dot{S} C S O . C_{10} H_{17}$.

(Diese Substanz wurde aus der Sendung von Herrn Tschugaew bestimmt.)

Für diese orangerot gefärbte Substanz ${ }^{1}$ ) gilt das Complexsymbol $4 \mathbf{h} ; 8$. 66

Aus diesem Symbol ersieht man sogleich, daß die zugehörige Modalität mit der vorigen identisch ist. Dieser Complex zeichnet sich besonders durch den außerordentlichen Wert der unteren Zahl aus.

Wäre diese Abweichung, welche jetzt die Winkelgröße von $7^{0} \mathrm{umfaBt}$, noch um einen halben Grad größer gewesen, so hälten wir für solche

1) Welche von Herrn Artemjew und dem Verf. früher in $*$ Bulletin des Natural. de Moscou « 1906, 1 u. 2 beschrieben wurde. Refer. in dieser Zeitschr. 46, 216. 
specielle Modalitäten zweiter Art die Grenze zwischen den beiden Typen - dem kubischen und dem hypohexagonalen - überschritten, und der Complex wäre auf die bypohexagonale zu beziehen.

Für sämtliche andere Hauptstructurarten und Modalitäten ist diès nicht mehr der Fall; es befindet sich sozusagen eine Kluft zwischen den Krystallcomplexen der beiden Typen. Der einzige Ausnahmefall besteht für die Modalitäten der zweiten Art und der hexaëdrischen Hauptstructurart, also für den Fall, welcher gerade dem jetzt betrachteten am nächsten steht. Dieser vom Verf. bewiesene Satz wurde in der Form

$$
\begin{array}{cc}
6 & 4 \mathrm{~h} \\
-7 & =\stackrel{A}{-7} \\
-7
\end{array}
$$

ausgedrückt 1).

Für diesen Fall wurde folgende Combination constatiert:

\begin{tabular}{cccccccccc}
1 & 2 & 3 & 4,5 & 6,7 & 8 & 9,10 & 11,12 & 14,15 & 16,17 \\
001 & 100 & 010 & 101 & 011 & 110 & 111 & 102 & 012 & $1 \overline{1} 1$ \\
\hline 4,00 & 1,39 & 1,08 & 1,03 & 0,86 & 0,59 & 0,66 & 0,59 & 0,52 & 0,47
\end{tabular}

Aus dieser Tabelle ersieht man zugleich, daß es sich um einen sehr seltenen Fall solcher ideeller Formenentwicklung und zugleich eines stark positiven Complexes handelt, in welchem die ersten zwölf Flächen in der Reihenfolge ihrer Wichtigkeit nicht nur vorhanden sind, sondern sich auch einigermaßen durch die Constanz in dieser Entwicklung auszeichnen. In dieser Reihenfolge fehlt überhaupt nur das 13. Glied $\{1 T 0\}$, für welches die Dichtigkeitsgröße gleich 0,53 ist, welche übrigens, practisch genommen, dieselbe ist, wie für die folgenden Glieder der Reihe.

Wie in meiner Grundarbeit bewiesen wurde, gibt es eine kolossale Anzahl von Modalitäten, welche wir erfahrungsmäßig unterscheiden können, und der erste Platz kommt in dieser Hinsicht den triklinen Krystallen zu, sodaß die Anzahl der Modalitäten der triklinen Krystalle allein die Anzahl aller übrigen Modalitäten zusammengenommen übertrifft.

Beim jetzigen Stande unserer Kenntnisse treffen wir eine ganz entgegengesetzte Verteilung der Krystalle, indem gerade die triklinen Complexe am schwächsten vertreten sind, und dabei schwächer als alle übrigen Syngoniearten, besonders als die rhombische und die monokline, welcher letzteren durchaus der erste Platz zukommt.

In Zukunft sind aber ganz andere Verhältnisse zu erwarten, da mit der stets zunehmenden Complicierung der chemischen Zusammensetzung der neu dargestellten Substanzen das beobachtete Verhältnis immer mehr zugunsten der triklinen geändert werden wird. In bezug auf die überhaupt möglichen Modalitäten kann man sagen, daß die jetzigen, zur chemischen Bestimmung dienenden Tabellen sich fast als leer erweisen.

1) Annales de l'Institut des mines à St. Pétersbourg 3, 93. . 
Jetzt liegt mir ob, die Operationen zu erläutern, mittelst welchen sich das Complexsymbol für alle Fälle ermitteln läßt. Sämtliche Modalitäten der triklinen Krystalle besonders zu betrachten, ist practisch unausführbar. Aber es muß doch eine ziemlich mannigfaltige Auswahl derselben zu dem gestellten Zwecke getroffen werden.

Gerade aber infolge der seltenen Vertretung der triklinen Krystalle und außerordentlich großen Anzabl von hierzu gehörenden Modalitäten, erwies es sich als unmöglich, sich mit den zur Bestimmung gekommenen triklinen Substanzen zu begnügen. Unter den hierzu gehörenden Substanzen (also triklinen von hexaëdrischer Hauptstructurart) ist keine einzige vorgekommen.

Es mögen für den aufgestellten $Z$ weck folgende drei Beispiele genügen.

\section{Trikline Syngonie.}

8. Beispiel. Natriumsilicowolframat-Ikosihydrat

$$
\mathrm{N}_{12} \mathrm{SiO}_{40} \mathrm{Na}_{4} \cdot 20 \mathrm{H}_{2} \mathrm{O} \text {. Mod. } \alpha \text {. }
$$

Für dieses Salz gibt Marignac ${ }^{1}$ ) folgende Combination; die Flächenpole ersieht man aus dem Diagramm.

$$
4 \mathrm{~h} ;+52
$$

Das Complexsymbol ist jetzt $61 . ; 0$.

$$
1 \text {. }
$$

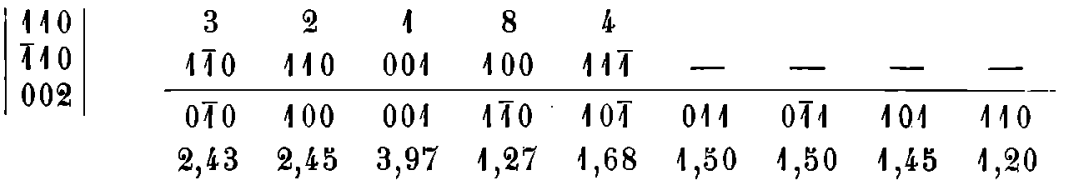

Wir ersehen aus dieser Tabelle, daß nur fünf Flächen(-paare) zur Beobachtung gekommen sind; welche somit sämtlich als wichtige Complexflächen zu betrachten sind, und daß gerade diese fünf Formen bis auf eine einzige mit der theoretischen Reihenfolge übereinstimmen.

Nun erbalten wir für $R=2,43+2,45+3,97+1,27+1,68=11,80$ für $J$ erhalten wir fast dieselbe Summe; nur 1,27 ist durch 1,50 zu ersetzen, also $J=12,03$, und der Factor $\frac{R}{J}=0,98$.

Die beobachtete Formenentwicklung steht also der ideellen sehr nahe.

Für diesen Fall, wie für die triklinen Krystalle überhaupt, besteht das Complexsymbol aus zwei Gliedern; das erste, einzeln genommen, drückt die Zugehörigkeit zu monoklinen Complexen und dabei eine ganz bestimmte Modalität aus.

Um also das Symbal des triklinen Complexes zusammenzufassen, muß

1) Annal. chim. phys. 1864, (4) 3, 57. Ref. in Groth's Chem. Kryst. 2, 633. 
eine Operation vorgenommen werden, welche denselben in den monoklinen überführt. Das ist die Operation der triklinen Verschiebung, und zum Ausdruck derselben dient gerade das zweite Glied des Symbols.

In monoklinen Complexen gibt es aber eine Symmetrieebene und die zu derselben senkrechte zweizählige Symmetrieaxe. Wird die der triklinen entgegengesetzte Verschiebung ausgeführt, so verschwindet zugleich die Symmetrieebene als solche; da aber dieselbe zugleich eine mögliche Complexfläche ist, so treffen wir also in triklinen Krystallen diese Fläche als eine besondere, welche durch die trikline Verschiebung in die Lage der Symmetrieebene übergeführt wird. Diese besondere Fläche der triklinen Krystalle bezeichnen wir als deren Pseudosymmetrieebene, und als Merkmal für dieselbe dient ihre Eigenschaft, nach welcher der Pol derselben mit der Axe der respectiven unter allen Zonen den minimalen Winkel bildet.

In dem jetzt betrachteten Falle ersehen wir direct aus dem Diagramm z. B., daß für die Zone [001] dieser Winkel gleich $5^{0}$; für die Zone [100] beträgt dieser Winkel ebenfalls etwas über 50 ; nicht geringere Größe erhält dieser Winkel auch für die Zonen [110], [1T0], [101], [T01], [011], [0T1]; aber für die Zone $[010]$ wird die Größe dieses Winkels nur durch etwa 20 ausgedrückt. Folglich sind gerade die Flächen von $\{010\}$ als diejenigen angenommen, welchen die Pseudosymmetrieebene parallel ist. Warum gerade diese Form durch $\{010\}$ und nicht durch $\{100\}$ bezeichnet wird, ist aus den oben gegebenen Erläuterungen klar geworden.

Nun orientieren wir das Diagramm so, daß die Pole von $\{010\}$ mit den bestimmten Hauptpolen des stereographischen Netzes zusammenfallen, und dann zeichnet sich die Pseudosymmetrieebene durch die größte Annäherung an einen monoklinen Krystall am anschaulichsten aus.

Die Größe des auf diese Weise ermittelten minimalen Winkels ist zugleich die Größe der triklinen Verschiebung. Denken wir nämlich eine solche ausgeführt, sodaß die Pseudosymmetrieebene zu einer wirklichen Symmetrieebene des Complexes wird, so muß der Pol $v$ derselben mit dem Pol von $\{010\}$ zusammenfallen; zugleich nimmt die verschobene Zone [010] dieselbe Lage an, wie bei echten monoklinen Krystallen.

Somit bewegt sich der Pol bei der Ausführung der Operation dieser Bewegung in einer Zone, welche durch die beiden Punkte: $v$ und den Pol von (010) eindeutig bestimmt ist. Wir suchen den Schnittpol dieser Zone mit der Symmetriezone und lesen, den Winkel derselben mit dem Pol (100) ab (also den Winkel zwischen der erwähnten Zone und der Hauptzone, welche durch den Projectionskreis vertreten ist). In diesem Falle steht dieser Winkel der Größe 0 sehr nahe; das ist die untere Zahl des zweiten Gliedes des Symbols, während die obere Zahl desselben Gliedes die Größe der triklinen Verschiebung bezeichnet.

Wir ersehen daraus, daß für diesen Fall in bezug auf das zweite Glied 
des Symbols uns eine Übergangsmodalität vorliegt, da in allen anderen Fällen im allgemeinen der Winkel, welcher durch die untere Zahl vertreten ist, nicht gleich 0 ist, also entweder eine positive oder eine negative Größe ist, was verschiedene Modalitäten bezeichnet, während wir hier einen besonderen $\mathrm{Z}$ wischenfall haben.

Denken wir uns nun die trikline Verschiebung wirklich ausgeführt, so kommen sämtliche Pole von der Zone [010] in die Trace der Symmetrieebene des monoklinen Complexes, und dabei bewegen sich diese sämtlichen Pole in den durch den Pol von (010) bestimmten Meridianen. Also wissen wir jetzt von vornherein, wohin diese Pole nach der erfolgten Verschiebung endlich gelangen; im besonderen kommt der Pol von (100) in den Punkt $A$, der Pol von (001) genau in die genannte Trace, ebenso wie der Pol von (T01).

Zugleich bewegen sich aber sämtliche anderen Pole in den erwähnten Meridianen, und nun ist es sehr leicht, die Strecke der respectiven Bewegung für jeden Pol zu bestimmen.

$\mathrm{Zu}$ diesem $\mathrm{Z}$ wecke ziehen wir eine, sonst beliebige, aber zur Pollinie (010)(0T0) parallele Gerade, deren Mittelpunkt der Punkt $a$ ist.

Auf dieser Geraden merkt man die Punkte $a_{1}$ und $b_{1}$ respective auf den Radien von (100) und ( $1 \bar{T} 0)$, und führt nun die wirkliche Verschiebung auf dieser Geraden aus, bis $a_{1}$ in die Lage $a$ kommt; dann kommt $b_{1}$ in die Lage $b_{1}{ }^{\prime}$ (folglich sind die Strecken $a_{1} a=b_{1} b_{1}{ }^{\prime}$ ). Auf diese Weise erhält man die richtige Lage für den $\mathrm{Pol}(1 \bar{T} 0)$ nach der erfolgten Verschiebung. Dabei zeigt es sich, daß der Winkel $(100):(1 T 0)$ um 1 $\frac{1}{2}$ Grad von $45^{0}$ abweicht. (Genau dieselbe $A$ bweichungsgröße hätten wir mittelst derselben Operation auch für den Pol (110) erhalten, da, nach der erfolgten Schiebung derselbe in die zum ersten symmetrische Lage kommt.) Somit ist aber zugleich die untere Zahl des Symbols ermittelt. Da aber gerade dieser Winkel größer ist als $45^{0}$, so muß derselbe der Winkel $(100):(1 T 0)$ und nicht der Winkel $(040):(1 \overline{1} 0)$ sein; dadurch sind die Flächensymbole bestimmt, wenn dabei noch berücksichtigt wird, daß hier die Modalität der ersten und nicht der zweiten Art vorliegt. Es muß noch der. Winkel (100):(001) in Rücksicht kommen, welcher für die Modalitäten erster Art geringer (keinenfalls größer) als $90^{\circ}$ angenommen wird. Dadurch wird $(100)$ von $(\bar{T} 00)$ unterschieden.

Mittelst einer Operation derselben Art erhält man die-endgültige Lage (also nach der Verschiebung) des Poles von (T11), obgleich die Fläche selbst in dem Complexe nicht vertreten ist. Diese Lage wird eigentlich durch zwei Verschiebungsoperationen bestimmt.

Zuerst verschiebt man die Strecke $(\bar{T} 01)(T 11)$ auf ihrem Meridiane, wobei der Pol der letzteren Fläche durch o bezeichnet ist. Dieser sphärischen Strecke entspricht die gerade Strecke $c c_{1}$ auf der Hilfsgeraden, und eigentlich wird diese gerade Strecke der Verschiebung unterworfen, aus 
der Lage $c c_{1}$ in die Lage $a c_{1}^{\prime}$; der $\mathrm{Pol}(\bar{T} 01)$ kommt genau in die Trace der Symmetrieebene, entsprechend dem Punkte $a$, der Pol o lrommt in die Lage $o_{1}$ entsprechend dem Punkte $c_{1}{ }^{\prime}$.

Die zweite Verschiebung bezieht sich auf die Strecke $(001):(T 01)$, indem der erste Pol endgültig in das Projectionscentrum kommt. Dieser Strecke entspricht auf der Hilfsgeraden die Strecke $d d_{1}$, welche in die Lage $a d_{1}^{\prime}$ verschoben wird. Auf diese Weise finden wir den Punkt $D$, welcher dem Punkte $d_{1}{ }^{\prime}$ entspricht (und vom Mittelpunkt 51 $\mathbf{1}_{2}{ }^{0}$ absteht). Die endgültige Lage des Poles von (T11) bestimmt die Zone (T01)(010) nach der erfolgten Verschiebung, folglich auch den Pol $o_{1}^{\prime}$, welcher Durchschnittspunkt dieser Zone mit der von (100) und Punkt $o_{1}$ ist. Natürlich muß $o_{1}{ }^{\prime}$ in dem Durchmesser von (1T0) liegen (nach der erfolgten Verschiebung ihres Poles).

Mit der Bestimmung der Lage des Pols $o_{1}{ }^{\prime}$ ist zugleich die Hauptzahl (61.)des Symbols bestimmt ${ }^{1}$ ).

9. Beispiel. Dibromtellurdiphenyl Mod. II $\begin{aligned} & \mathrm{C}_{6} \mathrm{H}_{5} \\ & \mathrm{C}_{6} \mathrm{H}_{5}\end{aligned}>\mathrm{Te}<\mathrm{Br}$

Diese trikline Substanz wurde von Herrn Billows ${ }^{2}$ ) untersucht und $4 \mathrm{~h} ;+17 \mathrm{~s}$.

hat zu dem Complexsymbol 48. $\quad ;-70$ geführt.

$-\frac{1}{2}$

Man faßt für dieselbe folgende Tabelle zusammen:

\begin{tabular}{c|cccccccccccc}
121 & 4 & 1 & - & 9 & 2 & 5 & 3 & 7 & & & & \\
002 & 100 & 010 & 001 & 110 & 101 & $\overline{111}$ & $2 \pi 0$ & $2 \overline{2} 3 ;$ & - & - & - & - \\
101 & $\frac{1}{101}$ & 100 & 121 & $10 T$ & 010 & 110 & 001 & 165 & $(011 ?)$ & $1 T 0$ & 011 & 111 \\
& 3,12 & 7,04 & 1,00 & 1,80 & 5,80 & 3,12 & 3,64 & - & 2,63 & 3,02 & 1,97 & 1,76
\end{tabular}

Auch ín diesem Falle haben wir eine der idealen sehr nahe stehende Formenentwicklung, besonders wenn wir die nach der Transformation der Indices erhaltene Form (165) als (011) auffassen würden: hier sind alle fünf erste Formen beobachtet, und die Form (011) wäre eigentlich die siebente.

Aus dem Diagramm ersehen wir die Besonderheiten dieser Modalität, zunächst darin, daß hier die abwesende Form $\{1 T 0\}$ als die Pseudosymmetrieebene erkannt ist; also gehört sie zu den Modalitäten zweiter Art, und für solche werden die größer als $90^{\circ} \mathrm{zu}$ messenden Winkel bevorzugt ${ }^{3}$ ).

1) Die hier erläulerten graphischen Verfahren, ebenso wie viele andere, welche zu der einfachsten Auflösung verschledener krystallographischer Aufgaben dienen, sind in unserer Schule jahrelang in Gebrauch. Eine systematischere Darlegung einiger derselben ist in den Annalen des Berginstituts zu St. Petersburg 3, 141 enthalten.

2) Rivista di miner. e cryst. ital. 1902, 28, 33. Ref. in dieser Zeitschr. 40, 290.

3) Meiner Ansicht nach wäre es zweckmäßiger, diese Regel auch für die Moda- 
Demzufolge erhält unter den Hauptflächen der Hauptzone diejenige die Indices (110), welche mit (100) und $(010)$ größere Winkel bildet als (1T0); dabei muß auch der Winkel $(100):(001)$ größer als $90^{\circ}$ sein. Durch diese Bedingungen sind aber auch sämtliche anderen Indices bestimmt.

Die Hauptzahl 48. bedeutet diejenige Winkelgröße (001):(111), welche nach der erfolgten triklinen und monoklinen Verschiebung sich ermitteln läßt. Die untere Zahl ist jetzt mit dem Zeichen - angenommen, um die Modalität als solche zweiter Art zu bezeichnen. Der oberen Zahl (also der monoklinen Verschiebungsgröße) 17 ist + beigegeben, um den Umstand zum Ausdruck zu bringen, daß hier der Pseudosymmetrieebene die Flächen von $\{1 \bar{T} 0\}$ parallel sind (wären dies die Flächen $\{110\}$ gewesen, so würde das Zeichen - beigegeben sein).

Aus der Lage des Poles $v$ ersieht man die Coordinaten des zweiten Gliedes des Complexsymbols; darunter bezeichnet die obere Zahl $5 \mathbf{1}_{2}{ }^{0}$ die trikline Verschiebungsgröße; das Zeichen - bei der unteren Zahl weist darauf hin, daß der Meridian (1T0) $v$ mit dem Projectionskreise $70^{\circ}$ mißt (wenigstens ungefähr, da diese Zahlen die gröbsten sind unter allen Zahlen des Symbols), aber auf der anderen Seite der Hemisphäre liegt, als der Meridian der Zone (1T0):(001).

Wie man sieht, zeichnet sich dieser Complex durch besonders starke monokline Anorthosität aus, welche sebr selten vorkommt (das Wort Anorthosität drückt die centrale Entfernung der Hauptfläche (004, resp. 1000 oder 111) aus.

10. Beispiel. Rubidiumbexacyanoferroat 2 aq. $\mathrm{Fe}(C N)_{6} R b_{4}, 2 \mathrm{H}_{2} \mathrm{O}$.

Diese trikline Substanz wurde von Herren Piccard und Wyrouboff $4 \mathrm{~h} ; 3 \quad 1$.

untersucht und hat zum Complexsymbol $77 . ;$ ? geführt.

Für dieselbe ließ sich folgende Tabelle aufstellen:

\begin{tabular}{|c|c|c|c|c|c|c|c|c|c|c|c|c|}
\hline \multirow{2}{*}{$\mid \begin{array}{ll}0 & \\
01 \\
20\end{array}$} & $\begin{array}{c}-1- \\
100 \bar{T} 00\end{array}$ & $\begin{array}{c}-5- \\
0 \overline{1} 0 \quad 010\end{array}$ & $\overline{110}$ & $\overline{110}$ & $\overline{01 \overline{1}}$ & $\overrightarrow{0 \bar{T} 1}$ & $\begin{array}{c}3 \\
101\end{array}$ & $\begin{array}{c}4 \\
001\end{array}$ & $\overline{011}$ & $\overline{101}(?)$ & & \\
\hline & 001001 & $0 T 0 \quad 010$ & 012 & 012 & $11 \pi$ & TT1 & $\bar{T} 0 \bar{T}$ & T01 & $T 11$ & $\overline{1} 0 \overline{3}$ & 100 & 011 \\
\hline
\end{tabular}

Aus dieser Tabelle ersieht man deutlich die für hochpositive Complexe charakteristische Reihenfolge der Formen. Dabei dominiert die erste Form

litäten I. Art (also allgemein) gelten zu lassen, da bei dieser Annabme die wlchtigeren Flächen seltener negative Indices erhalten. Aber in der Versammlung der ersten Teilnehmer in der krystallochemischen Analyse (Herren Artemjew, Barker, Sokolow und ich) wurde beschlossen, für die Modalitäten I. Art geringere Winkel als 900 vorzuziehen, da dies mehr den in der Krystallographie üblichen Regeln entspricht. 
in solchem Grade, daß alle übrigen fast ganz zu vernachlässigen sind. Man sieht, daB selbst die zweite Form (100) nicht auftritt, aber dieser Umstand spielte für den Aufstellungswert eine zu unbedeutende Rolle.

In der Tat haben wir

$$
\begin{aligned}
& \text { für } R=4,00+0,36+0,34+0,34+0,25=5,29, \\
& \text { für } J=4,00+0,38+0,36+0,34+0,34=5,42 .
\end{aligned}
$$

Also ist $\frac{R}{J}=\frac{529}{542}=0,98$.

Für diese Modalität ist die Hauplzahl (also der Winkel (001):(111) nach der erfolgten Verschiebung, trikliner wie monokliner) gleich 77. Sie gehört zu den Modalitäten zweiter Art, weil der Winkel (110):(1T0) dem rechten näher kommt als der Winkel $(100):(010)$. Infolgedessen werden, wie oben erklärt wurde, die Winkel von einer $90^{\circ}$ übersteigenden Größe bevorzugt. Also müssen die beiden Winkel $(100):(010)$ und $(100):(001)$ größer sein als $90^{\circ}$. Diese Bedingungen sind für die Bestimmung der Flächenindices entscheidend, da dabei noch die allgemeine Regel gilt, daß $(100):(110)$ größer sein muß als $(010):(110)$.

Für diese Modalität, als solcher zweiter Art, ist also die untere Zahl 310 (also die Abweichungsgröße des Winkels $(100):(110)$ von $45^{\circ}$, nach der erfolgten Verschiebung gemeint) mit dem Zeichen - zu schreiben.

Da jetzt die Fläche (001) der Pseudosymmetrieebene parallel ist, so ist die obere Zahl (3) ohne jedes Zeichen geschrieben (weder + noch - ).

Was endlich das zweite Glied des Symbols anbetrifft, so ist seine obere Zahl (die Größe der triklinen Verschiebung) nur $1 \frac{1}{2}{ }^{0}$ groß; diese Größe ist insofern unbedeutend, als es graphisch fast unmöglich ist, die untere Zahl mit genügender Genauigkeit (sogar auf 50) zu ermitteln, weshalb einfach? steht.

\section{b. Oktaëdrische Hauptstructurart.}

\section{Rhombische Syngonie.}

\section{Beispiel. Eisendiantimonid $\mathrm{FeSb}_{2}$.}

(Diese metallisch aussehende Substanz wurde aus der Zusendung von Herrn $K$ u rnak ow in kurzer Zeit bestimmt.)

\section{0}

Für diese Substanz ließ sich das Complexsymbol 37. ermitteln. Die 3

Combination wurde hauptsächlich durch zwei erste Formen, nur mit Andeutung der dritten Form, vertreten:

$$
\begin{array}{rrr}
110 & 011 & 010 \\
\hline 27,2 & 12,3 & 12,4
\end{array}
$$

Die Formenentwicklung ist nicht ideal, da für $\{101\}$ die Dichtigkeitsgröße 14,0 und für $\{100\} 14$. beträgt. 
Also erhalten wir für $R=27,2 \times 2+12,3 \times 2+12,4=91,3$ und $\frac{R}{J}=0,94$. und für $J=27,2 \times 2+14,0 \times 2+14,8=97,2$

Der Vergleich mit der Beschreibung von Herrn Isküll zeigt, daß derselbe die Form (010) gar nicht erwähnt hat (diese Zeitschr. 43, 376).

12. Beispiel. Dibenzoylcinnamenimid $\mathrm{C}_{22} \mathrm{H}_{17} \mathrm{NO}$.

(Diese Substanz wurde in der Zusendung von Herrn Barker bestimmt.)

40

Das Complexsymbol ließ sich als 54 ermitteln.

$-5$

Die gefundene Combination erwies sich als:

\begin{tabular}{cccc}
1 & 6 & $2,3,4,5$ & - \\
110 & 110 & 101 & 111 \\
\hline 8,44 & 6,40 & 7,32 & 1,38
\end{tabular}

Man ersieht, daß für die sechs ersten Flächen die Formenentwicklung sich als ideal erwies. Auf Grund der Erfahrung hätte man sich sogar mit den ersten fünf Flächen begnügen können. Wenn die Form $\{111\}$ theoretisch auch als eine von ganz untergeordneter Bedeutung betrachtet werden muß, muß sie doch als constant die Individualität des Complexes charakterisieren.

Aus dem Complexsymbol ersieht man, daß hier die Modalität zweiter Art vorliegt, und nur unter dieser Annahme hätten wir die ideale Formenentwicklung erhalten.

Aber, wie bekannt, können wir denselben Complex anders auffassen, sodaß die Modalität erster Art sein würde und dann von dodekaëdrischer Hauptstructurart. Dann hätten wir für das Symbol desselben den Aus$4 \mathrm{~d}$

druck 47. gehabt, was aber, wegen Eindeutigkeit der Ausdrücke, nicht ge5

stattet ist, weil die Hauptzahl sich unter $50^{\circ}$ erweist.

Der erste Autor der krystallographischen Beschreibung dieser Substanz Herr Tutton, diese Zeitschr. 18, 549) hat in der Combination mehrere fandere Formen angegeben.

Monokline Syngonie.

13. Beispiel. 1:4-Chlorobromobenzol-2-sulfo-or thotoluidid

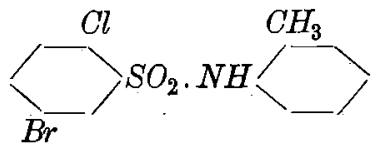

(Die Substanz wurde aus der Zusendung von Herrn Barker bestimmt.)

Das Complexsymbol erwies sich als $40 ;+12$. 


\begin{tabular}{ccccc}
1,2 & 3 & 4 & 5 & 6 \\
110 & 101 & 100 & 101 & 010 \\
\hline 34,24 & 13,68 & 9,74 & 9,28 & 7,04
\end{tabular}

Hier liegt ein Beispiel der durchaus idealen Formenentwicklung vor. Der Vergleich mit der Beschreibung von Herrn Colgate und Rodd ${ }^{1}$ ) zeigt vollständige Übereinstimmung; nur mußten, den jetzigen Forderungen gemäß, die Indices etwas abgeändert werden.

Auf dem Diagramm ist die monokline Verschiebung angemerkt, welche nötig ist, um das Complexsymbol zu ermitteln. Übrigens fand diese Operation oben genügende Erläuterung.

14. Beispiel. Kaliumferrioxalat-Hexahydrat $\left(\mathrm{C}_{2} \mathrm{O}_{4}\right)_{6} \mathrm{Fe}_{2} \mathrm{~K}_{6} .6 \mathrm{H}_{2} \mathrm{O}$. (Diese grasgrüne Substanz wurde aus der Zusendung von Herrn Barker bestimmt.)

Das Complexsymbol erwies sich als $40 ; 7^{-4}$.

\begin{tabular}{ccccc}
1 & 3,4 & 5,6 & 7,8 & - \\
110 & 101 & 100 & 011 & .112 \\
\hline 29,3 & 25,2 & 25,0 & 23,5 & 3,62
\end{tabular}

Aus dieser Tabelle ersieht man das Fehlen einer der wichtigsten Formen des Complexes $\{1 \bar{T} 0\}$, deren Dichtigkeitsgröße 28,2 ist, und zugleich das Erscheinen der Form $\left\{1 T^{2} 2\right\}$ von untergeordneter Bedeulung.

Nun erhalten wir

$$
\text { für } R=29,3+2 \times 25,2+2 \times 25,0+23,5=153,2
$$

und für $J=29,3+28,2+2 \times 25,2+2 \times 25,0=157,9$.

Also $\frac{R}{J}=0,97$.

Das Fehlen dieser Form ist also eine wichlige Besonderheit des Complexes. Dieses Fehlen ist aber kein absolutes, da in der vollständigeren Übersicht der Formen (Chem. Krystallogr. von Groth, 3, 168) diese Form (als 100) erwähnt (in der beigegebenen Abbildung aber nicht gezeichnet) ist.

Die betreffende Modalităt ist die zweiter Art, weshalb die Winkel größer als $90^{\circ}$ bevorzugt sind, also (100):(001) größer als $90^{\circ}$ genommen ist.

Der oberen Zahl ist das Zeichen - beigegeben, weil jetzt die Flächen $\{110\}$ der Symmetrieebene parallel sind (das Zeichen + hätte als solche Flächen 1 T0 bezeichnet).

1) Journ. Chem. Soc. London 1910, 97, 1595. 
15. Beispiel. Kaliumsalz des Orthonitrophenols $\mathrm{C}_{6} \mathrm{H}_{4}(\stackrel{1}{\mathrm{OK}}) \stackrel{2}{\mathrm{NO}} \mathrm{O}_{2} \cdot \mathrm{H}_{2} \mathrm{O}$.

(Diese orangerote Substanz wurde aus der Zusendung von Herrn Barker nicht bestimmt.)

Es wurden drei Krystalle mit fast identischen Resultaten gemessen. Aus diesen Messungen wurde geschlossen, da $B$ dieselbe rhombisch ist, aber eine Besonderheit aufweist, und zwar das Auftreten der Form $\{\overline{1} 30\}$ nur einseitig, was mit der Annahme von rhombischer Syngonie schlecht übereinstimmt.

4.0

Das Complexsymbol wurde als 42. angenommen, und diesem Symbol 6

würde keine Substanz der Tabellen entsprechen. Somit war die Bestimmung miBlungen, und ich befrug brieflich Herrn Barker über die Substanz; die Antwort steht im Titel.

Dann erwies sich, daß das früher angenommene Complexsymbol unrichtig war, und zwar infolge davon, daß die Form, welche von Herrn Barker als $\{120\}$ bezeichnet wurde, für die bestimmende angenommen, während in meinen Messungen sie vollständig abwesend war.

Aber das aus der Messung gefundene Symbol kann auch nicht ganz richtig sein, da nach Herrn Barker's Messung, die ausführlicher als die meinige war, die Substanz monoklin ist, und das richtige Complexsymbol $40 ; 1$

muß 42 heißen. Dasselbe ist aber dem von mir gefundenen so nahe, 6

daß es zweifellos erscheint, daß die Substanz richtig bestimmt worden wäre, falls in den Tabellen auch mein Symbol zugrunde gelegt würde.

Auf Grund meiner Beobachtungen wurde folgende Tabelle zusammengefaßt:

\begin{tabular}{cccc}
1,2 & 3 & 6,7 & 8 \\
110 & 100 & 011 & 010 \\
\hline 19,7 & 12,5 & 10,6 & 8,16
\end{tabular}

Aus der Tabelle ersehen wir, daß bei der beobachteten Combination die Form $\{101\}$ fehlt, welcher die Dichtigkeitsgröße 12,1 entspricht.

Folglich erhalten wir

für $R=2 \times 19,7+12,5+2 \times 10,6+8,2=81,3$

und für $J=2 \times 19,7+12,5+2 \times 12,1+10,6=86,7$, also $\frac{R}{J}=0,94$.

In diesem Falle steht die obere Zahl (1) ohne jedes Zeichen + oder -; weil jetzt der Symmetrieebene des Complexes die abwesenden Flächen $\{001\}$ parallel sind. 
Von Herrn Barker wurden außer den von mir gefundenen noch einige andere Formen constatiert (diese Zeitschr. 44, 157).

\section{Trikline Syngonie.}

16. Beispiel. $\alpha$-Dibrominosittetracetat $\mathrm{C}_{6} \mathrm{H}_{6}\left(\mathrm{O} . \mathrm{C}_{2} \mathrm{H}_{3} \mathrm{O}\right)_{4} \mathrm{Br}_{2}$. (Diese Substanz wurde aus der Zusendung von Herrn Barker sehr leicht bestimmt.) $40 ;-5 \quad 2$

Das Complexsymbol erwies sich als $44 ; 0$.

\begin{tabular}{cccccccccc}
1 & 2 & 3 & 4 & 5 & 6 & 7 & 8 & - & - \\
170 & 110 & 101 & $0 T_{1}$ & 101 & 100 & 011 & 010 & $21 \overline{1}$ & $12 \pi$ \\
\hline 17,7 & 17,1 & 11,6 & 11,4 & 11,2 & 9,5 & 9,4 & 7,0 & - & -
\end{tabular}

Aus dieser Tabelle ersieht man, daß sogar die ersten acht Formen in der ideellen Reihenfolge stehen, und gerade dieser Umstand erleichtert sehr die richtige Bestimmung.

Die beobachtete Combination stimmt vollständig mit der von Herrn Barker angegebenen (Chem. Kryst. v. Groth 3, 610).

Da die betreffende Modalität erster $\Lambda$ rt ist, so sind die weniger als $90^{\circ}$ messenden Winkel bevorzugt, also $(100):(001)$, wie $(100):(001)$, kleiner als $90^{\circ}$ angenommen; wenn man noch in Betracht zieht, daß $(100):(110)$ größer sein muß als $(010):(110)$, so findet man eindeutig die aufgesteliten Flächensymbole und da die Flächen $\{100\}$ der Pseudosymmetrieebene parallel sind, so ist der oberen Zahl das Zeichen - beigefügt.

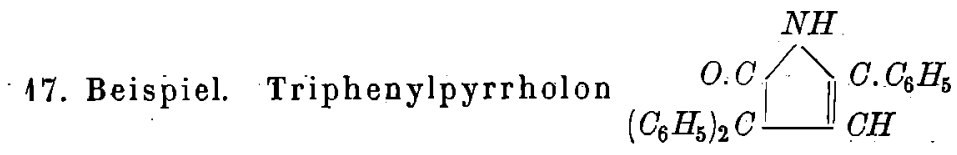

(Die Substanz wurde aus der Sendung von Herrn Barker bestimmt.)

$$
40 ;-14 \quad 12 \text {. }
$$

Das Complexsymbol ${ }^{-}$erwies $\operatorname{sich}^{-44^{-}} \quad ;+60$

\begin{tabular}{cccccc}
1 & 2 & 3 & 4 & 6 & 7 \\
$1 \overline{1} 0$ & 110 & 100 & 101 & 101 & 011 \\
\hline 21,3 & 14,8 & 14,8 & 14,0 & 10,0 & 7,6
\end{tabular}

Aus der Tabelle ersieht man, daß in der theoretischen Reihenfolge das fünfte Glied $\{0 \overline{1}\}$, für welches die Flächendichtigkeit gleich 13,4 ist, fehlt.

Folglich erhalten wir für $R=21,3+14,8+14,8+14,0+10,0=74,9$, während für $J$ dieselbe Summe mit der Ersetzung von 10,0 durch 13,4, also 78,3 und dann für $\frac{R}{J}=\frac{74,9}{78,3}=0,96$ sich ergibt.

Der Vergleich mit den Resultaten des ersten Erforschers dieser Substanz (Herr Tutton in dieser Zeitschr. 18, 551) zeigt, daB derselbe ge- 
rade diese fehlende Form wirklich beobachtet hat und folglich die echt ideelle Formenentwicklung constatierte.

Es braucht hier nicht besonders erläutert zu werden, was unter der unteren Zahl des zweiten Gliedes des Complexsymboles verstanden wird und was darin das Zeichen + ausdrücken soll. Ändert sich dieses Zeichen in -, so künnen wir schon die andere Modalität unterscheiden, und an der Grenze zwischen beiden soll 0 stehen, in welchem Falle die Übergangsmodalität besteht. Gerade für das vorige Beispiel haben wir eine solche Übergangsmodalität gehabt.

In diesem Beispiel haben wir zugleich den Fall einer extrem großen Anorthosität; nur sehr wenige Substanzen zeichnen sich durch noch größere Anorthosität aus.

18. Beispiel. Amaranthit $\mathrm{SO}_{4}(\mathrm{Fe} \cdot \mathrm{OH}) \cdot 3 \mathrm{H}_{2} \mathrm{O}$.

$40 ; 7 . \quad 6$

Das Complexsymbol erweist sich als $49 \cdot ;+80$ $-7$

Dieser Complex ist besonders deswegen erwähnt, um anschaulich zu zeigen, daß, obgleich auch hier die untere $\mathrm{Zahl}-7$ ist, man doch keine Andeutung an eine Annäherung an den Complex des hypohexagonalen Typus findet. Wie aber erklärt wurde, ist dies lediglich für die hexaëdrische Hauptstructur der Fall.

Dies ersieht man noch deutlicher aus der Reihenfolge der Dichtigkeitsgrößen.

Für dieses von Herrn Genth aufgestellte und von Herrn Penfield krystallographisch untersuchte Mineral ist eine ziemlich flächenreiche Combination angegeben:

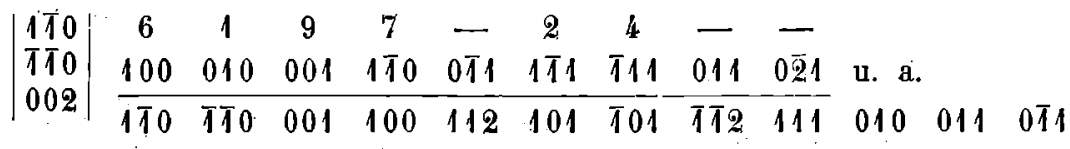

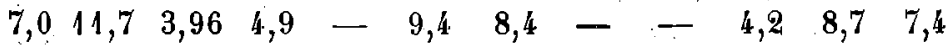

Aus dieser Tabelle ersieht man zugleich einen ziemlich großen Mangel an Ubereinstimmung der beobachteten Formenentwicklung mit der ideellen.

Man erhält nämlich für $R=11,7+9,4+8,4+7,0+4,9=41,4$ und für $J=11,7+9,4+8,7+8,4+7,4=45,2$

Also ist $\frac{R}{J}=\frac{414}{452} \doteq 0,92$.

Wenn hier also die Abweichung von 1,00 schon 0,08 (resp. 8\%) beträgt, so ist doch diese Größe nicht besonders ungewöhnlich, und sehr oft treffen wir noch größere Abweichungen. 
Da diese Modalität zu denen der zweiten Art gehört $\left.{ }^{1}\right)$, so sind die über $90^{0}$ messenden Winkel bevorzugt, d. h.: hier sind für $(100):(001)$, wie für $(100):(010)$ die größeren Winkel als $90^{\circ}$ angenommen. Dadurch ist zugleich eindeutig die Bezeichnung durch Flächensymbole bestimmt, wie dieselbe in dem Diagramm gezeigt worden ist.

Die obere Zahl (7.), d. h. die Größe der monoklinen Verschiebung ist ohne \pm -Zeichen angegeben, da in diesem Falle die Flächen $\{001\}$ der Pseudosymmetrieebene des Complexes parallel sind.

\section{c. Dodekaëdrische Hauptstructurart. \\ Rhombische Syngonie.}

Merkwürdigerweise kam unter den mir zugesandten Substanzen keine einzige vor, welche zu Modalitäten der ersten Art gehörte, dagegen eine Anzahl von solchen der zweiten Art. Infolgedessen bin ich gezwungen, für die erste ein Beispiel aus den Tabellen auszuwählen.

\section{Beispiel. Ferrodiuranylacetat-Heptahydrat}

$$
\left(\mathrm{CH}_{3} \mathrm{CO}_{2}\right)_{6}\left(\mathrm{CO}_{2}\right)_{2} \mathrm{Fe} .7 \mathrm{H}_{2} \mathrm{O} \text {. }
$$

$4 \mathrm{~d}$

Das Complexsymbol erweist sich als 50 .

Darauf fußt die Tabelle:

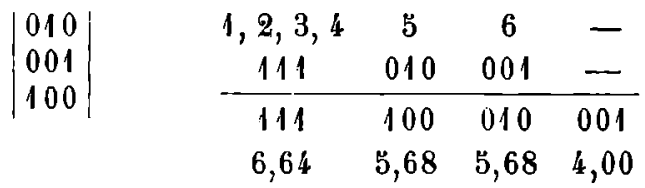

Man ersieht aus dieser Tabelle, daß die sämtlichen sechs Flächen mit der theoretischen Reihenfolge übereinstimmen, also die Formenentwicklung die ideelle ist.

20. Beispiel. Ammoniumoxalat-Monohydrat $\mathrm{C}_{2} \mathrm{O}_{4}\left(\mathrm{NH}_{4}\right)_{2}, \mathrm{H}_{2} \mathrm{O}$. (Diese Substanz ließ sich leicht aus der Zusendung von Herrn Groth bestimmen.)

Das Complexsymbol erwies sich als $\begin{gathered}4 \mathrm{~d} \\ 52 \\ -1\end{gathered}$

Die betreflende Tabelle ist:

$$
\begin{array}{ccccc}
1,2 & 3,4 & 7 & 9 & - \\
111 & 1 \overline{1} 1 & 001 & 1 \overline{1} 0 & 3 \overline{1} 1 \\
\hline 6,08 & 5,64 & 4,0 & 2,19 & -
\end{array}
$$

1) Weil (wie oben erklărt wurde) der Winkel $(110):(1 \overline{1} 0)$ dem rechten näher ist, als der Winkel (100): (010). 
Die letztere dieser Formen wurde unvollzählig entwickelt beobachtet, was klar ihre untergeordnete Bedeutung zutage treten läßt.

Aus dieser Tabelle ersehen wir das Fehlen der Form $\{100\}$ mit der Dichtigkeitsgröße 4,44, auch von (110) mit der Größe 2,43. Die Formenentwicklung ist nicht ideell, aber eigentlich von derselben wenig abweichend.

Ziehen wir, wie gewöhnlich, nur die ersten fünf Flächen in Betracht, so erhalten wir für $R=12,16+11,28+4,00=27,44$ und für $J=12,16+11,28+4,44=27,88$

Also $\frac{R}{J}=\frac{2744}{2788}=0,98$.

Der Vergleich mit den Resultaten der Messung der früheren Autoren (Groth's Chem. Kryst. 3, 150) zeigt, daß dieselben noch einige andere Formen beobachtet haben.

\section{Monokline Syngonie.}

21. Beispiel. Phtalylphenylhydrazid; I. Mod.

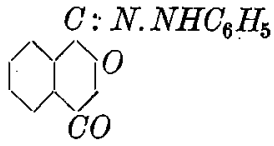

(Diese Substanz . wurde in der Sendung von Herm Barker bestimmt.)

Diese Substanz würde zu den besonders leicht bestimmbaren gerechnet werden können, wenn nicht ein besonderer Umstand, welcher die Krystallisation derselben zu den Ausnahmen stellt, bei der Bestimmung groß̣en Zweifel erregt hätte.

Dies wird aus dem Folgenden ersichtlich. Zuerst aber wird die Tabelle $4 \mathrm{~d} ;+3$. gegeben, welche auf dem Complexsymbol 71 basiert. 3

\begin{tabular}{cccc}
1 & 2,3 & 4,5 & - \\
001 & $\overline{1} 11$ & 111 & $\overline{101}$ \\
\hline 3,98 & 1,80 & 1,60 & 0,91
\end{tabular}

Außer den angegebenen waren auch andere Formen zur Beobachtung gelangt, welche aber einen fast zufälligen Charalter zeigten, indem unter fünf gemessenen Krystallen entweder keine von ihnen erschienen oder verschiedene von ihnen an verschiedenen Krystallen zum Vorschein kamen.

Das merkwürdigste ist aber die Tatsache, daß zu diesen Formen auch fast die Form zuzurechnen wäre, welcher eine stark ausgezeichnete theoretische Wichtigkeit zukommt, da dieselbe nur an zwei Krystallen constatiert wurde und dabei ausschließlich von ihr kein Signalreflex sichtbar (also für dieselbe nur. Schimmermessung zulässig) war.

Hätten wir dieselbe wirklich den zu vernachlässigenden zugerechnet, so würden wir für die Aufstellung einen ganz geringen Wert erhalten. 
Aus sämllichen, elwa 10000 Substanzen, welche in meinen Listen Platz gefunden haben, kommen derartige Fälle natürlich außerordentlich selten vor, sodaß ich sogar Zweifel gehegt habe, ob nicht in diesen Fällen die Autoren der Krystallmessung einfach vergessen hätten, diese, vielleicht stets tafelige, also vorherrschende, Formen in Erwähnung zu bringen. In einem mir zugänglichen Falle ${ }^{1}$ ) erwies es sich wirklich so.

Die übrigen drei Formen erschienen an allen beobachteten Krystallen. Ziehen wir die wichtigste Form nicht in Rechnung, so erbalten wir einen ganz unzulässig kleinen Aufstellungswert; wird dieselbe in Rechnung gesetzt, so ergibt sich für alle beständigen fünf ersten Formen die ideelle Formenentwicklung.

Solche Schwierigkeiten für die Theorie der Krystallstructur zu überwinden, ist Sache der Zukunft. Aber schon jetzt erkennen wir, daß es solche Beimengungen (als solche kann ausnahmsweise sogar die lösende Substanz erscheinen?) gibt, welche das Auftreten sogar der wichtigsten Formen des Complexes verhindern. Es wäre also die Krystallisation dieser Substanz aus anderen Lösungen zu erproben.

\section{Beispiel. Cocosit $\mathrm{C}_{6} \mathrm{H}_{6}(\mathrm{OH})_{6}$.}

(Diese Substanz wurde aus der Zusendung des Herrn Barker leicht bestimmt.)

$$
4 \mathrm{~d} ;-2
$$

Das Complexsymbol wurde als 57 . erkannt.

$$
-7
$$

Darauf fußt die Tabelle:

\begin{tabular}{ccc}
1,2 & 5 & 6,7 \\
111 & 111 & 100 \\
\hline 4,64 & 2,76 & 2,27
\end{tabular}

Aus dieser Tabelle ersehen wir eine ziemlich große Abweichung von der ideellen Formenentwicklung, indem von den ersten fünf Flächen diejenigen fehlen, welchen der dritte und vierte Platz in dem Complexe zukommt, und zwar ist die Dichtigkeitsgröße für (001) 4,00 und für (1T1) 3,24.

Wir erhalten für $R=2 \times 4,64+2,76+2 \times 2,27=16,58$ und für $J=2 \times 4,64+4,00+3,24+2,76=19,28$

Also $\frac{R}{J}=\frac{1658}{1928}=0,86$.

Auch hier haben wir eine extraordinär große untere Zahl, d. h. Abweichung von der ideellen Winkelgröße $45^{\circ}$.

Nun hat die Erfahrung gelehrt, daß diese zwei die Bestimmung hindernden Unstände - die extraordinäre Größe für die untere Zahl und

(1) In dem Falle von Meta-Nitranilin (diese Zeitschr. 42, 9). 
die ziemlich große Abweichung von der ideellen Formenentwicklung - in Wirklichkeit keine Schwierigkeiten dargeboten haben, da die Bestimmung sofort erfolgte.

Der Vergleich mit den Resultaten des ersten Autors der Krystallmessung dieser Substanz, Herrn Barker (Chem. Krystallogr. von Groth $3,6+2)$, zeigt, daß von demselben auch $\{1 T 1\}$ beobachtet wurde.

Wie Herr v. Groth in seiner Chemischen Krystallographie $(3,604)$ angegeben hat, ist diese Substanz wahrscheinlich identisch mit Quercin. In der Tat sind beide in bezug auf complexiale Eigenschaften nicht zu trennen und daher in meinen Tabellen durch einen einzigen Punkt vertreten.

Man sieht auch aus dem beigegebenen Diagramm, daß trotz der extraordinären Größe der unteren Zahl, welcher dabei das Zeichen - beigegeben ist (was sie zu den Modalitäten zweiter Art zuzurechnen nötigt) von einer Annäherung an die Complexe des hypohexagonalen Typus keine Rede sein kann.

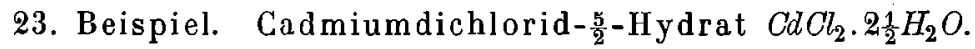

Auf Grund der Beobachtungen von Herrn Bömer ${ }^{1}$ ) ist folgende Tabelle $4 \mathrm{~d} ; 3$

zusammengefaßt und zugleich das Complexsymbol 50 aufgestellt. $-2$.

\begin{tabular}{|c|c|c|c|c|c|}
\hline $\bar{T} 00$ & 6 & 3,4 & 1,2 & - & - \\
\hline 001 & 001 & 111 & T11 & 010 & - \\
\hline & 010 & T11 & 111 & 001 & 100 \\
\hline & 4,76 & 5,92 & 6,64 & 4,00 & 5,28 \\
\hline
\end{tabular}

Aus der Tabelle ersieht man schon direct, daß die Abweichung von der ideellen Formenentwicklung hier nur sehr gering ausgefallen ist. In der Tat erhält man jetzt für $R=2 \times 6,64+2 \times 5,92++^{\circ}, 76=\mathbf{2 9 , 8 8}$ und für $J=2 \times 6,64+2 \times 5,02+5,28=30,40$. Also $\frac{R}{J}=0,98$.

Dieselbe Combination mit noch einigen anderen Formen hat auch Herr Fock beobachtet ${ }^{2}$ ). Nun siebt man jetzt klar, daß derjenigen Formenliste der Vorzug zu geben ist, welche die kürzere, also beständigere ist, resp. welche wichtigere Formen enthält.

1) Diese Zeitschr. 35, 203 ; referiert aus N. Jahrb. f. Miner. 1899, 2, 79.

2) Ebenda 35, 406. 


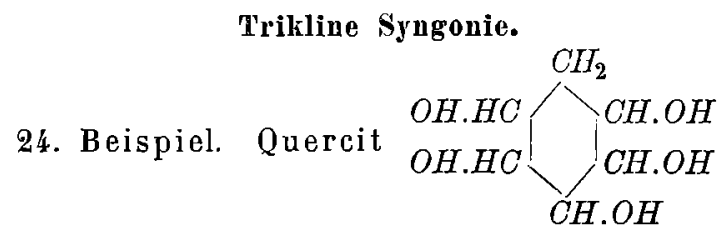

(Diese Substanz wurde aus der Sendung von Herrn v. Groth bestimmt.)

$$
4 \mathrm{~d} ;-3 \cdot 1
$$

Das Complexsymbol erwies sich als 62. $;+$ ?

3

Das Fragezeichen in dem zweiten Gliede des Complexes, hier wie in ziemlich vielen anderen Fällen, wird gesetzt, weil es bei den verhältnismäßig gröberen graphischen Operationen ganz unmöglich erscheint, bei geringeren oberen Zahlen (der triklinen Verschiebung) diese Zahl sogar in Grenzen von $10^{\circ}$ richtig zu stellen. Aus dem beigegebenen Diagramm ersieht man aber deuilich, daß hier + gesetzt werden muß.

Es fand sich in der Sendung ein Krystall, welcher alle Flächen der der folgenden Tabelle enthielt:

\begin{tabular}{ccccccc}
1 & 2 & 3 & 4 & 5 & 7 & - \\
001 & 1T1 & 111 & $1 T 1$ & 111 & 010 & 011 \\
\hline 3,98 & 3,48 & 3,44 & 3,33 & 3,28 & 1,89 & 1,25
\end{tabular}

Diese Formenentwicklung kann im engeren Sinne als die ideelle bezeichnet werden, da die ersten fünf Flächen nach ihrer Wichtigkeit vertreten gefunden wurden; es fehlt die sechste Fläche $\{100\}$ mit der Dichtigkeitsgröße 2,62, welche zugleich als die der Pseudosymmetrieebene parallele erscheint; deswegen ist die obere Zahl des ersten Symbolgliedes mit versehen.

Die gemessenen zwei Krystalle zeichnen sich nicht durch besonders gute Flächenbeşchaffenheit aus, soda $B$ es möglich ist, zuzulassen, daß die Größe 1 der triklinen Verschiebung in den Fehlergrenzen stehen kann.

Aber früher habe ich an besten Krystallen derselben Substanz nicht nur aus den Messungszahlen, welche viel genauer waren, sondern durch directe optische Beobachtung nachgewiesen ${ }^{1}$ ), daß dieselbe wirklich triklin ist.

Damals wurde ein anderes Complexsymbol aufgestellt, und zwar $30 ;-1.1$

61 ; ? Also wurde der Complex den trigonaloïden zugerechnet, und -5 .

zwar nach diesem Symbol (nach dessen Zahlen auch der Punkt in den Tabellen bestimmt wurde). Es ergab aber die erneute Untersuchung für diesen, den hexagonaloïden, wie den tetragonaloïden Complexen nahe stehenden Complex, da $\beta$ es sogar genauer ist, denselben den letzteren zuzu-

1) Diese Zeitschr. 41, 455 . 
rechnen, wie man direct durch den Vergleich der Complexsymbole ersieht (die untere Zahl des Symbols ist jetzt 3 anstatt 5.) und wenn man die ideelle Formenentwicklung bei dieser Aufstellung in Rücksicht zieht.

Ich glaube mich mit diesen 24 Beispielen für die tetragonaloïden Krystalle begnügen zu können, da darin so verschiedenartige Modalitäten vertreten sind, daß hoffentlich kein Zweifel mehr entstehen kann, wie man im einen oder anderen Falle zu verfahren hat, um diejenigen Complexsymbolzahlen zu ermitteln, durch welche die betreffende Substanz direct aus den Tabellen ihre Bestimmung findet. Mit Absicht wurden auch Übergangsglieder zwischen verschiedenen Modalitäten, ebenso wie einige den extremen näher stehende Beispiele herangezogen.

Was die trigonaloïden Complexe betrifft, so glaube ich, in Anhetracht der Parallelität derselben mit den tetragonaloïden, dieselben kürzer behandeln zu dürfen.

2. Trigonaloĩde (Hexagonaloïde vom kubischen Typus).

a. Hexaëdrische Hauptstructurart.

Monokline Syugonie.

25. Beispiel. Phtalyl-paratolyl-hydrazid

(Diese Substanz wurde aus der Zusendung von Herrn Barker bestimmt.)

Das Complexsymbol erwies sich als 63

$$
3 \mathrm{~h} ;+11
$$

Die beobachtete Combination erwies sich als ${ }^{1}$ ):

\begin{tabular}{cccccc}
1,2 & 3 & 5,6 & 7,8 & 9 & - \\
100 & 001 & 101 & $\overline{1} 01$ & $1 \overline{1} 0$ & $11 \bar{T}$ \\
\hline 0,88 & 0,80 & 0,47 & 0,36 & 0,34 & 0,30
\end{tabular}

Es fehlt also nur die Form $\{110\}$, deren Dichtigkeitsgröße 0,66 ist und welcher somit der vierte Platz im Complex zukommt.

Wir erhalten für $R=2 \times 0,88+0,80+2 \times 0,47=3,50$ und für $J=2 \times 0,88+0,80+0,66+0,47=3,69$.

1) Was die Bestimmung der reticulären Dichtigkeiten der trigonaloïden Krystalle anbetrifft, so erbält man, wie in der oben citierten Arbeit von Herrn Sokolow und Artemjew (diese Zeitschr. 46, 377) erklärt wurde, die betreffenden Zahlen direct durch Ablesung der Centralwinkeldistanzen für alle schiefen Flächen. Für die Flächen der Hauptzone ist es aber nötig, zuerst die Indices mit (111) zu addieren. Für (1T0) construiert man den Pol von (201) (Punkt $a$ auf dem Diagramm), für (10 $\bar{\tau})$ den Pol von (210) (Punkt b). Nach der erfolgten Verschiebung erhält man resp. die Punkte $a^{\prime}$ (also Centraldistanz -490) und $b^{\prime}$ (Centraldistanz 480). 
Also $\frac{R}{J}=\frac{350}{369}=0,95$.

Was das Complexsymbol anbetrifft, so ist nur das Zeichen + der oberen Zahl zu erläutern; dieses Zeichen bedeutet nämlich, daß der Pol von $\{111\}$ nicht in derselben, sondern in der anderen Hemisphäre als die Pole (100) und (010), folglich in derselben wie (001), liegt.

Für die trigonaloïden Krystalle wird die Hauptzahl nicht vón (001), sondern von (100), (resp. 010) bis (111) abgelesen (nach der erfolgten Verschiebung). Dies empfiehlt sich, da dadurch (bei etwaigen Ungenauigkeiten) der durchschnittliche Winkel (aus zweien) gefunden wird.

Die untere Zahl hat eine und dieselbe Bedeutung für alle hexagonaloïden Krystalle. Im betrachteten Falle ist die doppelte $\mathrm{Zahl}-2$. (also $5^{0}$ ), die Abweichungsgröße des Winkels $(1 \bar{T} 0):(T 01)$ von $60^{\circ}$.

26. Beispiel. Rohrzucker (Saccharose) $\mathrm{C}_{12} \mathrm{H}_{22} \mathrm{O}_{11}$.

(Diese Substanz wurde aus der Zusendung von Herrn Groth bestimmt.)

Das Complexsymbol erwies sich als 62 .

$3 \mathrm{~h} ;-\mathrm{-4}$.

-2 .

Die beobachtete Combination erwies sich einfach:

\begin{tabular}{cccc}
1 & 2,3 & 6 & - \\
001 & 100 & 110 & $1 \overline{12}$ \\
\hline 1,03 & 0,80 & 0,52 & 0,14
\end{tabular}

Es fehlen in der Combination die Flächen von $\{101\}$, denen die Dichtigkeitsgröße 0,64 zukommt (also der Platz 4 und 5).

Wir erhalten somit für $R=1,03+2 \times 0,80+0,{ }_{2} 2=6,15$ und für $J=1,03+2 \times 0,80+0,64=6,27$.

Also $\frac{R}{J}=\frac{615}{627}=0,98$.

Aus dem am vorigen Beispiel erläuterten Grunde ist jetzt der oberen Zahl das Zeichen - und nicht + zugeschrieben. Man sieht als Resultat, $\mathrm{da} B$ hier $\{001\}$ und nicht $\{100\}$ den ersten Platz einnimmt.

Die früheren Autoren der Krystallmessung dieser Substanz haben noch einige andere Formen beobachtet (vgl. Groth's Chem. Kryst. 3, 448).

Ich habe hier ein Beispiel angefübrt, in welchem die Bestimmung auf Grund der sich als unrichtig erweisenden Aufstellung geschah. In derselben Zusendung von Herrn Groth befand sich aber dieselbe Substanz in specieller Combination (Nr. 21), welche bei dieser unrichtigen Aufstellung nicht bestimmt wurde. Die richtige Aufstellung ist auf demselben Diagramm durch Kreise dargestellt und deren Übergang aus der unrichtigen durch punktierte Linien angedeutet. Dann erhält man als Complexsymbol 
$4 \mathrm{~d} ;-13$.

51. . In der Substanz Nr. 21 wurde die Combination: $111,1 \overline{1} 1,100$ -4 .

(unvollzählig) und 001 beobachtet.

\section{b. Oktaëdrische Hauptstructurart.}

\section{Monokline Syngonie.}

27. Beispiel. Isomorphe Gruppe $\left(\mathrm{SO}_{4}\right)_{2} \mathrm{NM}_{2} \cdot 6 \mathrm{H}_{2} \mathrm{O}$.

(Es wurden zwei Glieder dieser Gruppe zugesandt und bestimmt; aus der Zusendung von Herrn Groth das Glied $N=M g, M=K$ und aus der Zusendung von Herrn Barker das Glied $N=Z n, M=N H_{4}$; da die chemische Probe nicht ausgeführt wurde, was eigentlicb am zweckmäßigsten gewesen wäre, so ergab sich aus reinen Winkelverhältnissen das letzte Glied für $N=M g$.)

Die Combination für einzelne Krystalle erwies sich ziemlich veränderlich und meistens als sehr flächenarm. Aber nach der Ausführung der Messung von wenigen Krystallen ergab sich als Complexsymbol etwa $\begin{gathered}30 ;+10 \\ 48\end{gathered}$ und folgende Combination:

\begin{tabular}{cccccc}
1,2 & 3 & 4 & 5,6 & 9 & - \\
$10 T$ & $1 T 0$ & 110 & 101 & 001 & 310 \\
\hline 5,80 & 3,92 & 3,75 & 2,82 & 1,76 & 0,78
\end{tabular}

Aus dieser Tabelle ersieht man, daß für die ersten sechs Flächen sich die ideelle Formenentwicklung ergibt.

Schon oben (S. 518 u. 527) wurde auf die Constanz von $\{310\}$ als eine individuelle Besonderheit dieser Complexe hingewiesen.

\section{c. Dodekaëdrische Hauptstructurart.}

Monokline Syngonie.

28. Beispiel. 1:4-Bromochlorobenzol-2-sulfanilid<smiles>O=[R16]1CCCCC1Br</smiles>

(Nicht die Substanz selbst, sondern die Zugehörigkeit derselben zu einem Gliede der isomorphen Gruppe, welcher das gezeichnete Glied zugehört, wurde aus der $\mathrm{Zu}$ sendung von Herrn Barker bestimmt.)

Als Complexsymbol erwies sich 48 .

Als Complexsymbol erwies sich 48

Die beobachtete Combination ist:

\begin{tabular}{cccccc}
1 & 2 & 3,4 & 5 & 8 & - \\
111 & $11 T$ & $1 \overline{1} 1$ & 001 & $11 \overline{3}$ & $20 \bar{T}$ \\
\hline 3,96 & 3,08 & 2,76 & 2,25 & 1,00 & 0,25
\end{tabular}

Groth, Zeitschrift f. Krystellogr. I. 
Man ersieht aus dieser Tabelle, daß für die ersten fünf Flächen die Formenentwicklung ideell ist; der sechste und siebente Platz kommt der fehlenden Form $\{100\}$ zu, deren reticuläre Dichtigkeit gleich 1,70 ist. Das stetige Auftreten der achten Form $\{11 \overline{3}\}$ ist schon die individuelle Besonderheit des Complexes.

\section{Trikline Syngonie.}

Unter den zur Bestimmung zugesandten Krystallen kam kein einziger hierzu gehöriger vor.

Deswegen will ich als ein Beispiel eine Krystallsubstanz nehmen, welche in unserem Institut von Herrn Orelkin gemessen wurde und zugleich zu den sehr stark positiven und den echten trigonalen, als ideellen, sehr nahe stehenden ${ }^{1}$ ) gehört.

\section{Beispiel.}

Die Krystalle wurden von Herrn Demjanow dargestellt. Die Substanz ist Dinitrodiisopropyl $\left(\mathrm{CH}_{3}\right)_{2} \mathrm{C} . \mathrm{C}\left(\mathrm{CH}_{3}\right)_{2}$ und ist tafelig nach $\{111\}$. $\stackrel{1}{\mathrm{~N}} \mathrm{O}_{2} \stackrel{\mathrm{I}}{\mathrm{N}} \mathrm{O}_{2}$

$$
3 \mathrm{~d} ;+42
$$

Als Complexsymbol ergab sich 72. ; +70 .<smiles>[AlH2]</smiles>

Die beobachtete (für sieben gemessene Krystalle identische) Combination ist folgende:

\begin{tabular}{cccccc}
1 & 2 & 3 & 4 & 6 & 7 \\
111 & $11 T$ & 100 & 111 & 010 & 001 \\
\hline 1,76 & 0,40 & 0,36 & 0,36 & 0,34 & 0,32
\end{tabular}

Man ersieht, daß die Formenentwicklung fast die ideale ist; es fehlt allein die Form $\{1 \bar{T} 1\}$, welcher die Dichtigkeitsgröße 0,36 zukommt und welcher ebenso der fünfte wie der vierte oder sogar der dritte Platz in dem Complex zuerteilt werden kann (die aus den Tabellen abzulesenden Zahlen sind schon in der zweiten Decimale nicht ganz sicher).

Für diesen Fall die Rechnung auszuführen, wäre zwecklos gewesen, da von vornherein ersichtlich ist, daß der Aufstellungswert der Einheit sehr nahe steht.

1) Die Resultate der Untersuchung wurden noch nicht publiciert. 


\section{Krystalle des hypohexagonalen Typus.}

\section{Rhombische Syngonie.}

\section{Beispiel. Isomorphe Gruppe des Kaliumsulfats.}

(Die Glieder dieser isomorphen Gruppe wurden in den Zusendungen der Herren Groth und Barker bestimmt.)

Unter den zugesandten Krystallen befinden sich sogar drei hierzu gehörende Substanzen (zwei vom ersten und eine vom zweiten dieser Gelehrten), und alle drei sind verschieden. Das $N H_{4}-\mathrm{Salz}$ ließ sich aber von den beiden anderen - $K$-Salz und $R b$-Salz - sogar ohne specielle chemische Probe unterscheiden.

Verschiedene gemessene Krystalle unterschieden sich in bezug auf den Fläcbenreichtum der: vertretenen Combination. Für das $R b$-Salz war die Combination sehr flächenarm, und daher stelle ich in das beigegebene Diagramm die Resultate der Messing des $K$-Salzes, für welches sich das 6

Complexsymbol als ว̈6 erwies.

0

Für manche Formen ließ sich die Übereinstimmung mit den Zahlen von Herrn Tutton ${ }^{1}$ ) bis auf die Minute constatieren, sodaß die Identität des $K$-Salzes mit den beschriebenen Krystallen außer jedem Zweifel stand.

Es wurde folgende Combination beobachtet:

\begin{tabular}{ccccccccc}
1 & 2 & 3,4 & 5,6 & $7,8,9,10$ & 11,12 & 13,14 & - & - \\
1000 & $010 \bar{T}$ & 0110 & $110 \bar{T}$ & 1110 & $210 \bar{T}$ & $021 \bar{T}$ & $410 \bar{T}$ & $230 \overline{3}$ \\
\hline 4,00 & 1,82 & 1,82 & 1,25 & 1,25 & 0,64 & 0,60 & 0,22 & 0,16
\end{tabular}

Man ersieht daraus, daß die ersten 14 Flächen in der Reihenfolge der idealen Formenentwicklung vertreten sind. Aber die Entwicklung der Formen selbst entspricht dieser Reihe nicht vollständig; umgekehrt ist gerade die erste Form sehr unvollständig entwickelt und fehlt oft; sie erscheint auch unvollzählig, wie dies stets für die beiden letzteren Formen beobachtet wurde. Die am meisten entwickelten Formen sind die der Zone [0121]. Alles dies ist als individuelle Besonderheit der betreffenden Complexe zu betrachten.

Die Hauptzahl des Complexsymbols, wie dies allgemein für die hypohexagonalen Krystalle gilt, ist die Winkelgröße (1000):(1110). Die obere Zahl 6 drückt natürlich die Zugehörigkeit des Complexes zum hypohexagonalen Typus aus. Die untere Zahl (0) läßt den Complex als Übergangsglied zwischen den Modalitäten auffassen, für welche diese Zahl mit + resp. mit - versehen wird; zugleich können solche Krystalle als die pseudo-

1) Diese Zeitschr. 24, s. 
hexagonalen im engeren Sinne betrachtet werden. Schon für den am nächsten stehenden Complex von Ammoniumsulfat ist diese Zahl durch $+\frac{1}{2}$ zu ersetzen, da der Winkel (010T):(0110) etwa 6010 beträgt. Dadurch wurde das Ammoniumsalz von den $K$ - und $R b$-Salzen unterschieden.

In dem hypohexagonalen Typus gibt es keinen solchen Unterschied zwischen den Modalitäten wie diejenigen erster und zweiter Art im kubischen Typus. Wenn also der eben erwähnte Winkel von $60^{\circ}$ um weniger als $\frac{1}{4}^{0}$ abweicht, so wird 0 gesetzt ohne Rücksicht auf die Minuten; im kubischen Typus sind im allgemeinen die Fälle, in welchen +0 resp. -0 gestellt wird, scharf zu unterscheiden.

$$
\text { 31. Beispiel. d- } \alpha \text { - } \alpha^{\prime} \text {-Dibromeampher } \begin{aligned}
& \mathrm{CH}_{2} \cdot \mathrm{CH}-\dot{C}\left(\mathrm{CH}_{3}\right)_{2} \\
& \mathrm{CH}_{2} . \dot{C}\left(\mathrm{CH}_{3}\right) . \mathrm{CO}
\end{aligned}
$$

(Diese Substanz wurde aus der Zusendung 1) von Herrn Barker bestimmt.)

Das Complexsymbol erwies sich als 40.

Die Combination war sehr einfach:

$$
+2
$$

\begin{tabular}{ccc}
1 & 2,3 & 5,6 \\
$010 \overline{1}$ & 0110 & $110 \bar{T}$ \\
\hline 6,19 & 5,68 & 2,42
\end{tabular}

Die vierte Form $\{1000\}$, welcher die Dichtigkeitsgröße 4,00 zukommt, trat nicht auf.

Also erhalten wir für $R=6,12+11,36+4,84=22,32$

$$
\text { und für } J=6,12+11,36+4,00+2,42=23,90
$$

und folglich $\frac{R}{J}=\frac{2232}{2390}=0,93$.

\section{Monokline Syngonie.}

32. Beispiel. Para-Nitrophenol $\mathrm{C}_{6} \mathrm{H}_{4}\left(\stackrel{1}{\mathrm{OH}} \stackrel{\mathrm{H}}{\mathrm{NO}_{2}}\right.$. Labile Mod.

(Diese Substanz wurde aus der Zusendung von Herrn Barker bestimmt.)

Das Complexsymbol erwies sich als $23 ;-3$. $-7$

Es wurde folgende Combination beobachtet:

\begin{tabular}{ccccc}
1,2 & 3 & 4 & 10,11 & - \\
0110 & $010 T$ & 0121 & 1110 & 2121 \\
\hline 21,2 & 14,8 & 8,5 & 3,3 & 0,9
\end{tabular}

1) Die Krystalle erwiesen sich als identisch mit denen, welche von Hro. Lowry beschrieben (Transact. Chem. Soc. London 1898, 73, 579; referiert in dieser Zeitschr. 32, 294), also für $C l . B r$ gehalten wurden. Herr Barker aber erklărte, daß dies die isomorphe Dibromverbindung ist. 
Es fehlen die Formen $\{021 T\}$, welcher die Dichtigkeitsgröße 5,3 , $\{1000\}$, welcher die Dichtigkeitsgröße 3,99, und $\{1011\}$, welcher die Dichtigkeitsgröße 3,5 zukommt.

Wir erhalten somit für $R=42,4+14,8+8,5+3,3=69,0$ und für $J=42,4+14,8+8,5+5,3=71,0$.

Also $\frac{R}{J}=0,97$.

Der Vergleich mit der originalen Beschreibung dieser Substanz durch Herrn Barker (diese Zeitschr. 44, 159) zeigt, daß die letzte Form sogar unerwähnt geblieben war.

Hier haben wir wieder den Fall, welcher an der Grenze zwischen dem hypohexagonalen und kubischen Typus (Modalität zweiter Art) und unbedingt hexaëdrischer Hauptstructur steht und der schon oben erwähnt wurde (vergl. 7. Beispiel).

Der oberen Zahl des Symbols ist - beigegeben, um auszudrücken, daß hier der Symmetrieebene des Complexes die Flächen von $\{0121\}$ (und nicht $\{010 T\})$ parallel sind. In diesem Falle werden derjenigen Fläche die Indices $(010 \overline{4})$ zuerteilt, welche mit $(1000)$ einen geringeren als einen rechten Winkel bildet.

Da in dem Zugesandten keine anderen hierzu gehörenden Modalitäten aufgefunden wurden, so erlaube ich mir die zwei folgenden Beispiele aus dem Mineralreiche zu entnehmen.

33. Beispiel. Symplesit $\left(\mathrm{AsO}_{4}\right)_{2} \mathrm{Fe}_{3} .8 \mathrm{H}_{2} \mathrm{O}$. Das Complexsymbol erwies sich als $\begin{gathered}6 ;+\frac{1}{2} \\ 21^{-6}\end{gathered}$.

Die von Herrn Krenner ${ }^{1}$ ) angegebene Combination ist:

\begin{tabular}{|c|c|c|c|c|c|}
\hline \multirow{3}{*}{$\left|\begin{array}{l}002 \\
331 \\
602\end{array}\right|$} & 3 & 1,2 & 4 & - & $\overline{013}$ \\
\hline & 010 & 110 & 100 & 001 & 013 \\
\hline & $010 \overline{1}$ & 0110 & 0121 & 2121 & 1110 \\
\hline & 19,24 & 27,16 & 9,84 & 0.91 & 3,49 \\
\hline
\end{tabular}

Man ersieht daraus, daß in solchem stark negativen Complex fast allein die Flächen der Hauptzone in Betracht kommen; für die fünfte Form $\{021 T\}$ besteht die DichtigkeitsgröBe 9,10 und sogar für $\{1000\}$ haben wir einen 4,00 sehr nahestehenden Wert.

Berücksichtigen wir die ersten fünf Flächen, so erhalten wir

$$
\begin{array}{r}
\text { für } \cdot R=2 \times 27,2+19,2+9,9+3,5=87,0 \\
\text { und für } J=2 \times 27,2+19,2+9,9+9,1=92,6
\end{array}
$$

1) Referiert in dieser Zeitschr. 13, 70. 
Also $\frac{R}{J}=\frac{870}{926}=0,94$.

Was die untere Zahl des Symbols und ihr Zeichen bedeutet, wurde schon erklärt. Was die obere Zahl anbetrifft, so ist das Zeichen + beigegeben, um auszudrücken, daß in diesem Falle der Symmetrieebene des Complexes die Flächen von $\{010 \bar{\tau}\}$ parallel sind (und nicht 0121 , wie im vorigen Falle). Als die Fläche (0121) wird diejenige ausgewählt, welche mit (1000) einen geringeren als einen rechten Winkel bildet.

\section{Beispiel. Epidot.}

$$
6 ; \frac{1}{2}
$$

Das Complexsymbol ist 35. . +4 .

Wenn wir an diesem, einem der gewöhnlichsten Minerale, nur die wesentlichsten, fast an allen Krystallen auftretenden Formen berücksichtigen ${ }^{1}$ ), so erhalten wir:

\begin{tabular}{|c|c|c|c|c|c|c|c|c|}
\hline \multirow{4}{*}{$\left|\begin{array}{lll}0 & 1 & 0 \\
0 & 01 \\
1 & 0 & 1\end{array}\right|$} & 3 & 1 & 2 & - & 6 & 7,8 & - & - \\
\hline & 100 & 001 & $\bar{T} 01$ & $\overline{2} 01$ & 101 & $\overline{1} 11$ & - & - \\
\hline & $00 \overline{1}$ & $010 \bar{T}$ & 0110 & 0121 & $01 \overline{1} 2$ & 1110 & $021 T$ & 1000 \\
\hline & 8,16 & 10,40 & 7,88 & 2,43 & 3,24 & 2,66 & 4,92 & 4,00 \\
\hline
\end{tabular}

Auf Grund der Tabelle finden wir

$$
\begin{array}{r}
\text { für } R=10,4+8,2+7,9+3,2+2,7=32,4 \\
\text { und für } J=10,4+8,2+7,9+4,9+4,0=35,4
\end{array}
$$

Also $\frac{R}{J}=\frac{324}{354}=0,92$.

Hier steht die obere Zahl ohne $\pm-Z$ Zeichen, um zu zeigen, daß in diesem Falle die Symmetrieebene des Complexes den Flächen $\{1000\}$ parallel ist. Als Form $\{010 \bar{T}\}$ wird diejenige ausgewählt, welche mit der zugeordneten Form $\{0121\}$ den dem rechten am nächsten stehenden Winkel bildet; dabei müssen die Flächen $(010 \bar{T})$ und (0121) keineswegs einen größeren als den rechten Winkel bilden.

\section{Trikline Syngonie.}

35. Beispiel. Aethyltriphenylpyrrholon

$$
\begin{array}{r}
\left(\mathrm{C}_{6} \mathrm{H}_{5}\right)_{2} \mathrm{C} . \mathrm{CH} \\
\dot{\mathrm{C} O} \ddot{\mathrm{C}} \mathrm{C}_{6} \mathrm{H}_{5} \\
\mathrm{~N}_{\mathrm{S}} \mathrm{C}_{2} \mathrm{H}_{5}
\end{array}
$$

(Diese Substanz wurde aus der Zusendung von Herrn Barker bestimmt.)

Das Complexsymbol erwies sich als $\begin{gathered}6 ;-13 \\ 49 \\ +3\end{gathered}$

1) Die statistische Behandlung dieses Minerals (eigentlich des Puschkinits von Werch-Isetskj wurde tabellarisch in den Annalen des Berginstituts zu St. Petersburg 1, 184 reproduciert. 
Die beobachtete Combination ist:

\begin{tabular}{cccccc}
1 & 2 & 3 & 4 & 5 & 8 \\
$010 T$ & 1000 & 0011 & 0110 & $1 T 01$ & $10 T T$ \\
\hline 3,86 & 3,78 & 3,24 & 2,92 & 2,42 & 1,62
\end{tabular}

Es fehlen nur die sechste Form $\{1 \bar{T} \overline{0} 0\}$ mit Dichtigkeitsgröße 1,86, und die siebente Form $\{1011\}$ mit Dichtigkeitsgröße 1,80. Die ersten fünf bilden aber die ideelle Combination.

Jetzt ist die (mögliche) Fläche (0121) des Complexes der Pseudosymmetrieebene des Complexes parallel, weshalb der oberen Zahl des Symbols das Zeichen - beigegeben ist. Die Indices (0121) und (1000) sind denjenigen Flächen zuerteilt, welche einen geringeren als den rechten Winkel bilden. Dasselbe ist in diesem Falle auch für $(010 \bar{T})$ geschehen, da dieselbe mit (0121) einen geringeren als einen rechten Winkel bilden muß.

Der Vergleich mit den Resultaten des ersten Autors der Krystallmessung dieser Substanz (Tutton, diese Zeitschr. 18, 560) zeigt, daß derselbe gerade die eben als fehlend erwähnten Formen und noch einige andere beobachtet hat.

36. Beispiel. Methyltriphenylpyrrholon $\begin{gathered}\left(\mathrm{C}_{6} \mathrm{H}_{5}\right)_{2} \mathrm{C.CH} \\ \stackrel{\mathrm{CO}}{\mathrm{O}} \ddot{\mathrm{C}} . \mathrm{C}_{6} \mathrm{H}_{5} \\ \underset{\mathrm{NCH}}{\mathrm{CH}}\end{gathered}$

(Diese Substanz wurde in der Zusendung von Hern Barker bestimmt.)

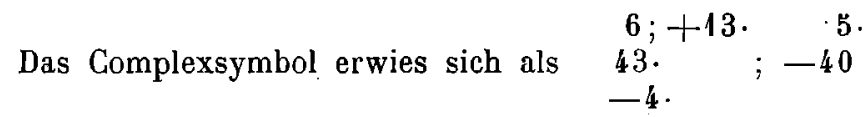

Die beobachtete Combination ist:

\begin{tabular}{ccccccccc}
1 & 2 & 3 & 4 & 5 & 6 & 7 & 8 & 10 \\
0011 & 0110 & 1000 & $010 \bar{T}$ & $10 \bar{\top} \mathrm{T}$ & $1 \overline{1} \bar{T} 0$ & $110 \overline{1}$ & 1110 & $1 \bar{T} 01$ \\
\hline 5,44 & 4,60 & 3,78 & 3,24 & 2,69 & 2,24 & 1,86 & 1,76 & 1,66
\end{tabular}

Aus dieser Tabelle ersieht man einen sehr seltenen Fall so weitgehender, ideeller Formenentwicklung: von den ersten zehn Gliedern fehlt nur der neunte, die Form $\{0121\}$, welcher die Dichtigkeitsgröße 1,68 zukommt.

Der erste Autor der Krystallmessung dieser Substanz (Tutton, diese Zeitschr. 18, 554) hat noch einige andere Formen beobachtet (aber nicht die neunte).

Die Pseudosymmetrieebene des Complexes ist jetzt den Flächen von der Form $\{010 T\}$ parallel (deswegen ist der oberen Zahl das Zeichen + beigegeben). Das Flächensymbol (010ग̃) ist derjenigen Fläche beigegeben, welche mit $\{0121\}$ den kleineren als den rechten Winkel bildet; auch die (mögliche) Complexfläche (0121) steht bei derjenigen der beiden, welche mit (1000) einen geringeren als den rechten Winkel bildet (trotzdem, daß 
in diesem Falle der Winkel $(010 \bar{T}):(1000)$ größer als ein rechter ist). Dadurch sind sämtliche Flächensymbole eindeutig bedingt.

Da hier kein Fall eines solchen triklinen Complexes angegeben wurde, in welchem die Flächen der Form $\{1000\}$ der Pseudosymmetrieebene parallel stehen (also die obere Zahl ohne \pm gesetzt wird), so ist der Vollständigkeit halber beizufügen, daß in diesem Falle angenommen wird, daß (0121) mit (010T) und mit (1000) kleinere Winkel bilden als $90^{\circ}$. Dadurch sind sämtliche anderen Flächensymbole des Complexes eindeutig bedingt.

In dem Vorhergehenden sind die Grundlagen der Operationen dargestellt, welche für die Ausführung der krystallochemischen Analyse nötig sind. Natürlich ist aber, daß nicht jede Substanz, welche in Krystallen gegeben ist, unbedingt bestimmt werden kann (falls dieselbe in den bestimmenden Tabellen aufgezeichnet ist). Die Krystalle müssen einigen minimalen Forderungen genügen, und die erste unter diesen ist die, daß nach der Messung von zwei oder mebreren Krystallen die beobachteten Formen identificiert werden können; bekanntlich kommen auch Fälle vor, in welchen diese Identification nicht möglich ist, und dann haben wir keine Constanz, auf welche die Bestimmung gegründet werden kann, was aber unbedingt nötig ist.

Daraus erhellt, daß es überhaupt als nötig gelten kann, für die Bestimmung nicht einen einzigen, sondern eine, wenn auch geringe, Anzahl von Krystallen zu haben. Natürlich kommen auch so einfache Fülle vor, daß sogar die Messung eines einzigen Krystalles zum Ziele führt, aber das sind eher die Ausnahmefälle.

Das ersieht man auch aus folgendem.

Als Grundprincip der krystallochemischen Analyse gilt die Męssung und Erkennung der wichtigsten, d. h. der in ihrem Auftreten constantesten Formen. Sind die Krystalle in einer Anzahl gemessen, so ersieht man direct durch den Vergleich der zusammengefaßten Diagramme, welche diese Formen sind; ein einziges Diagramm gibt auf diese Frage keine bestimmte Antwort. Als Regel kann es gelten, daß die wichtigsten zugleich die am meisten entwickelten Formen sind; diese Regel hat aber sehr viele Ausnahmen.

Außerdem ist zu berücksichtigen, daß die in der Beobachtung wichtigsten nicht zugleich sämtlich die theoretisch wichtigsten Formen sind; manche von ihnen sind sozusagen individuell (für die gegebene Substanz) wichtig und haben also große Bedeutung für diese individuelle Bestimmung, haben aber keine große theoretische Wichtigkeit in dem Complexe.

Natürlich sind auch die Krystalle der kubischen Syngonie zu solcher Bestimmung nicht geeignet.

Wenn das vorliegende Material zur krystallochemischen Analyse allen 
diesen Forderungen Genüge leistet, so sind doch Fälle denkbar, in welchen die Bestimmung in hohem Grade erschwert oder sogar fast unmöglich wird; es ist nur an die Abhängigkeit der Krystallisation von einigen äußeren Umständen zu erinnern. Demgemäß schien es bei Beginn der Operationen der krystallochemischen Analyse zweckmäßig, auf statistischem Wege die Wahrscheinlichkeit der Bestimmbarkeit der Substanzen zu ermitteln. Gerade zu diesem $Z$ wecke wurden in unserem Institut die Arbeiten in größerem Maßstabe während des akademischen Jahres 1910-1911 durchgeführt, von welchen hier berichtet werden soll.

$\mathrm{Zu}$ diesem $\mathrm{Zweck}$ wurde an einige Collegen die Bitte gerichtet, speciell für diese Prüfung uns schon beschriebene, aber nur mit Nummern versehene Substanzen zukommen zu lassen, und diese Bitte fand eine warme Aufnahme, sodaB im Institut eine ziemlich große Anzahl Substanzen in Krystallform gesammelt wurde, und es ist jetzt die erste Aufgabe, aus diesen Sendungen diejenigen Substanzen zu beseitigen, von welchen den zur Bestimmung nötigen Anforderungen nicht Genüge geleistet wurde.

Der erste Krystall für diese Analyse wurde von Herrn Kupffer übergeben; derselbe fand diesen sehr großen Krystall in der technischen Abteilung des Museums ohne jede Etikette. Diese erste Bestimmung, an welcher die Herren Sokolow und Artemjew beteiligt waren, geschah am 25. September 1910. Der letztere hat die Messung mittelst dem vom Verf. beschriebenen Universalanlegegoniometer ausgeführt ${ }^{1}$ ). Die Substanz erwies sich als $\mathrm{NiSO}_{4} .6$ aq. Die Bestimmung geschah in einer halben Stunde.

Die zweite Substanz wurde von Herrn Kurnakow zur Bestimmung übergeben, und dazu war nicht ganz eine Stunde erforderlich. Die Substanz erwies sich als $\mathrm{Fe}^{\mathrm{S}} \mathrm{Sb}$.

Von Herrn Tschugaew wurden drei Substanzen zugesandt. Die eine davon erwies sich als 1-Phenyl-2-Aethyl-31-Bornyl-Imidoxanthid; die zweite als Mentholdixanthogenat; die dritte wurde in den Tabellen nicht aufgefunden. Nach der Anfrage erwies sich diese Substanz als das trigonale Benzil, und dieselbe war wirklich in den Tabellen nicht aufgezeichnet; sie gehört zu den sehr leicht bestimmbaren.

Alle diese Bestimmungen wurden von Herrn Artemjew ausgeführt.

Herr P. v. Groth hat 28 Substanzen zugesandt, von welchen aber fünf Blättchen darstellen und eigentlich nicht für goniometrische, sondern für optische Bestimmung geeignet waren. Von den übrigen ist es in einigen Fällen nicht gelungen, die Formen zu identificieren (Nr. 6), ein Krystall war ein kubischer (Nr. 15 Natriumchlorat) und ein ausgezeichneter Krystall

1) Annalen des Berginstituts 2, 331. 
(Nr. 12) ein in engstem Sinne pseudokubischer. Einige Substanzen waren nur durch je einen einzigen Krystall vertreten (Nr. 11, 22, 231).

Von den übrigen 16 Substanzen wurden bestimmt:

1) Strontiumdithionat +4 aq (Nr. 4; da die chemische Probe nicht ausgeführt wurde, so wurde das isomorphe $C a$-Salz genannt);

2.) Kaliumlithiumsulfat ( $\mathrm{Nr} .7)$;

3) Baryumchlorid + 2aq (Nr. 13);

4) Ammoniummagnesiumdoppelsulfat +6 aq (Nr. 14);

5) Ammoniumsulfat (Nr. 16);

6) Kaliummagnesiumdoppelsulfat +6 aq (Nr. 17; dieses wie das Salz Nr. 4 durch chemische Probe verificiert);

7) Natriumdithionat +2aq (Nr. 18);

8) Ammoniumoxalat + aq (Nr. 19);

9) Glycosaminhydrochlorid (Nr. 20);

10) Quercit (Nr. 24);

11) Thalliumdithionat (Nr. 26);

12) Rohrzucker (Nr. 27);

13) Kaliumsulfat (Nr. 28; dieses Salz, wie Nr. 5, wurde durch chemische Probe verificiert).

Unbestimmt sind drei Substanzen geblieben, von welchen eine (der gütigen Mitteilung Herrn v. Groth gemäß), Nr. 10, vielleicht in meinen Tabellen nicht enthalten ist; das merkwürdigste ist aber die Nichtbestimmung der Substanz Nr. 21, welche sich wieder als Rohrzucker erwies, aber sich durch eine besondere Krystallisation auszeichnete. Vielleicht wäre es zweckmäßig gewesen, wie ich dies wirklich für sehr wenige Substanzen getan habe, solche in ihrer Ausbildung veränderliche Substanzen zweimal in die Tabellen mit verschiedener Aufstellung einzutragen ${ }^{2}$ ).

Herr Th. Barker hat mir 50 Substanzen in Krystallen zugesandt und hat diese neu auskrystallisieren lassen, wodurch dieselben natürlich noch leichter zur Bestimmung kommen (von allen lagen ziemlich viel Krystalle vor).

Trotzdem waren zwei von ihnen nicht bestimmungsfähig, und zwar Nr. 1, für welche sich die Formen nicht identificieren ließen, und Nr. 10, in welcher es eine ausgezeichnete pseudotetragonale Hauptzone und Hauptfläche (001) zu bestimmen gelang, aber keine schiefen Flächen vorbanden waren; wenigstens eine davon wäre für die Bestimmung ganz notwendig gewesen.

Es wurden von diesen 48 Substanzen folgende bestimmt:

1) Nr. 23 erwies sich als Asparagin, d. h. eine Substanz, welche wir für besonders leicht bestimmbar halten und dieselbe den Studierenden in unserem Institut für die erste Praxis in krystallochemischer Analyse geben.

2) Herr Groth hat die Substanz Nr. 21 als eine ihm unbekannte zugesandt. 
2) Eine Substanz aus der isomorphen Gruppe 1:4-Bromchlorbenzol2-sulfanilid;

3) 1:4-Chlorbrombenzol-2-sulfo-orthotoluidid;

4) 1:4-Chlorbrombenzol-2-sulfo-metatoluidid;

5) 1:4-Bromchlorbenzol-2-sulfanilid (isomorph mit Nr. 2);

7) Methyllriphenylpyrrholon;

8) Dibenzoylcinnamenimid;

9) Propyltriphenylpyrrholon;

11) Aethyltriphenylpyrrholon;

12) Triphenylpyrrholon;

13) Rubidiumnitrat;

14) Natriumnitrat;

15) Chromalaun (natürlich war diese Bestimmung eine ganz zufällige gewesen für einen kubischen Krystall);

16) Ammoniumzinkdoppelsulfat 6 aq (es wurde eigentlich das isomorphe Ammoniummagnesiumsalz genannt);

17) Dibrominosittetraacetat. Trikline Mod.;

18) $\alpha \alpha$-Dibromcampher (es wurde eigentlich die isomorphe Chlorbromverbindung genannt);

19) Ammoniumperjodat;

20) Paranitrophenol;

21) Rubidiumsulfat (es wurde eigentlich das isomorphe Kaliumsalz genannt);

23) Kaliumperchlorat;

24) Kupfersulfat $\stackrel{5}{a}$ aq;

25) Dihydrogenkaliumorthophosphat;

26) Kaliumnatriumtartrat (Seignette-Salz);

27) Natriummetaperjodat 6 aq;

28) Bromcamphersäureanhydrid;

30) Strontiumformiat $2 \mathrm{aq}$;

31) Quecksilberjodür;

32) Phtalylmethylphenylhydrazin;

35) Tetramethyltrijodmercuriat;

36) Cocosit;

37) Cäsiumperjodat;

39) Bisphenylmethylmethylenazin;

40) Saures Kaliumoxalat;

41) Dimethylmalonsäure;

43) Kaliumferrioxalat 6 aq;

45) 2.4-Dichlorphenylacetylstickstoffchlorid;

46) Paranitrophenol. Labile Mod.;

47) Phtalylparatolylhydrazid; 
49) Para-Dinitrobenzol;

๖0) Tetraphenylhydrazin.

Von den unbestimmten Substanzen erwies sich Nr. 22 als zweifelhaft. Auf Anfrage hat Herr Barker geantwortet, daß dies die labile Modification von Paranitrophenol sei, aber mein Diagramm stimmt damit nicht überein (möglicherweise hat eine Verwechslung stattgefunden, sodaß es eine in meiner Tabelle wirklich nicht aufgezeichnete Substanz war).

Auch die Substanz Nr. 29 kann fast als bestimmt betrachtet werden, denn das Complexsymbol wurde richtig aufgestellt; aber für diese tetragonale Substanz - l-Isocamphersäure - konnte ich keine voliständige Combination erhalten, da die Krystalle niemals isoliert auftraten, sondern in enger Verwachsung, sodaß ich stets nur abgebrochene Krystallteile zur Beobachtung hatte.

Endlich wurden von Herrn Duparc $\left.{ }^{1}\right)$ zur Bestimmung vier Substanzen erhalten, von welchen aber eine nicht bestimmt werden konnte, da an den Krystallen nur eine Zone und außerdem nur eine Fläche vertreten war.

Die übrigen drei erwiesen sich als:

1) Acetyldiphenylamin,

2) Strychninoxyd,

3) Beryll mit besonderer Combination (es erwies sich später, daß dieser rosa gefärbte Beryll von Madagascar stammt).

Vielleicht wäre das gesammelte Material hinreichend, um daraus den Schluß zu ziehen, daß bei dem jetzigen Stande der krystallochemischen Analyse zu erwarten ist, daß von vier untersuchten Substanzen mindestens drei bestimmt werden können.

Ich glaube, daß mit dem Erscheinen der krystallochemischen Analyse selbst die Aufgabe der geometrischen Krystallographie klarer gestellt wird. Wie anfangs dieser Arbeit betont wurde, gibt jede specielle Wissenschaft ihrem Vertreter eine specielle Macht in dem Gebiete der Naturerscheinungen, und wenn man nun fragt, welche Macht diese specielle Wissenschaft gibt, so ist jetzt zu antworten, daß in diesem Moment ihrer Geschichte sie in erster Linie die Macht gibt, die krystallochemische Analyse ausführen zu können, und diese ist meiner Anschauung nach keine zu vernachlässigende; vielleicht ist sie nicht geringer als die Macht von Chemikern, neue Substanzen zu schaffen und gewöhnliche chemische Analysen auszuführen. Es

1) Noch früher hat Herr Duparc eine kleine Anzabl von zienlich schlecht ausgebildeten Krystallen zugesandt, welche sich teilweise nicht bestimmungsfähig erwiesen, und von denen keine bestimmt wurde. Spater stellte sich heraus, daß sie zu neu beschriebenen gehören und in meinen Tabellen nicht enthalten sind. In einer neuen Zusendung, welche ich Herrn Orelkin übergab, bestimmte derselbe Selgnettesalz und Resorcin. Zwei andere waren schon verwittert (die Zusendung hatte anfangs des Sommers stattgefunden). 
ist also der Moment gekommen, sagen zu können: wer der geometrischen Krystallographie mächtig ist, kann die krystallochemische Analyse ausführen.

In der zweiten Linie steht jetzt die richtige Bestimmung der Formen, welche in der vorigen Periode für eine Sache der subjectiven Schätzung gehalten wurde. Mit der Zeit erwirbt diese zweite Macht noch größere Bedeutung als die erstere. Jetzt sind nur die ersten Schritte in dieser Richtung zu erwarten.

Ich erlaube mir, in dieser Hinsicht nur sehr wenige Bemerkungen zu machen über Verhältnisse, welche mir ganz zufällig bei der Zusammenfassung der Tabellen in die Augen fielen.

Ich sehe zwei Substanzen als identisch an, welchen man bis jetzt verschiedene chemische Zusammensetzung zuschrieb, und zwar 1) Trihydrogennatriumhypophosphat $4 \mathrm{aq}=\mathrm{P}_{2} \mathrm{O}_{6} \mathrm{NaH}_{3} .4 \mathrm{H}_{2} \mathrm{O}$ und 2) Dihydrogendinatriumhypophosphat 6 aq $=\mathrm{P}_{2} \mathrm{O}_{6} \mathrm{Na}_{2} \mathrm{H}_{2} .6 \mathrm{H}_{2} \mathrm{O}$. Der Vergleich der Diagramme weist auf fast völlige Identität nicht nur in den Winkelverhältnissen, sondern auch in der Combination hin, infolgedessen beide durch das Complex$6 ;-7$.

symbol 75. zum Ausdruck kommen.

Als zweites solches Beispiel weise ich auf die Substanzen hin, welche 1) als Monokaliumcarbonat $\mathrm{CO}_{3} \mathrm{KH}$ (als Mineral Kalicinit) und 2) als Tetrakaliumtricarbonat $2 \mathrm{CO}_{3} \mathrm{KH} . \mathrm{CO}_{3} \mathrm{~K}_{2} \cdot 3 \mathrm{H}_{2} \mathrm{O}$ beschrieben werden. Die Krystalle der beiden lassen sich durch ein und dasselbe Complexsymbol $\begin{gathered}6 ; \\ 18^{\frac{1}{2}} \\ -7\end{gathered}$ ausdrücken.

Meine dritte Bemerkung bezieht sich wahrscheinlich auf eine Etikettenverwechslung durch Haushofer. Man findet nämlich in Groth's Chem. Kryst. 3, 570 Dicyandiamid in zwei vollkommen verschiedenen Beschreibungen dargestellt, von welchen sich die eine auf eine rhombische und die andere auf eine monokline bezieht. Nun habe ich bei Abfassung der Tabellen bemerkt, daß das Complexsymbol der ersten Beschreibung fast identisch ist mil der Beschreibung einer ganz anderen Substanz — Methyl-

guanidin-Chloroaurat (ebenda 571); für die beiden ist das Complexsymbol 35 gültig.

Meine vierte Bemerkung bezieht sich auf eine und dieselbe Substanz: Kaliumnatriumcarbonat 12 aq (vgl. Chem. Kryst. 2, 199), welche als verschieden beschrieben und als isomorphe bezeichnet ist. Da die beiden durch das $4 \mathrm{~d} ;-5$

Complexsymbol 61. ihren Ausdruck finden und sich nur durch Reich1. 
tum von Combinationen unterscheiden, so glaube ich darin die Identität zu ersehen, welche Groth l. c. 190 als sehr wahrscheinlich betrachtet hat.

Weiter erlaube ich mir auf den Winkelisomorphismus ${ }^{1}$ ) der folgenden Reihe von Substanzen hinzuweisen (Metajodate mit Molybdaten und Wolframaten).

\begin{tabular}{|c|c|c|c|c|}
\hline$J_{2} O_{8}\left(N H_{4}\right)_{2}$ & $65^{0} \quad 4^{\prime}$ & $\mathrm{WO}_{4} \mathrm{Ca}$ & (Scheelit) & $65^{0} 10^{\prime}$ \\
\hline$J_{2} O_{8} L i_{2}$ & 6514. & $\mathrm{MoO}_{4} \mathrm{Ca}$ & (Powellit) & 6526 \\
\hline$J_{2} O_{8} K_{2}$ & 6532 & $\mathrm{WO}_{4} \mathrm{Sr}$ & & 6535 \\
\hline$J_{2} O_{8} R b_{2}$ & 6535 & $W_{4} R b$ & (Stolzit) & 6537 \\
\hline $\mathrm{J}_{2} \mathrm{O}_{8} \mathrm{~N} \mathrm{~F}_{2}$ & 662 & $\mathrm{MoO}_{4} \mathrm{Sr}$ & & 6548 \\
\hline $\mathrm{J}_{2} \mathrm{O}_{8} A g_{2}$ & 6625 & $\mathrm{MoO}_{4} \mathrm{~Pb}$ & (Wulfenit) & $\begin{array}{ll}66 & 13\end{array}$ \\
\hline $\mathrm{RuO}_{4} \mathrm{~K}$ & 6636 & $\mathrm{WO}_{4} \mathrm{Ba}$ & & 6628 \\
\hline
\end{tabular}

Hier sind die Hauptzahlen der betreffenden Complexe für diese tetragonalen Substanzen von dodekaëdrischer Hauptstructurart zusammengestellt.

Vielleicht wäre es richtiger gewesen, auch die Formeln der rechten Colonne zu verdoppeln (ebenso wie für das Ruthenat).

In manchen Fällen fielen mir die besonderen complexialen Verhältnisse zweier in bezug auf chemische Structur sehr nahe stehender Substanzen ins Auge.

Ich möchte mich für jetzt mit einem Beispiel begnügen, und zwar den merkwürdigen Verhältnissen zwischen zwei isomeren Substanzen (Monobromhexahydroterephtalsäuredimethylester), welche krystallographisch von Herrn Muthmann beschrieben wurden ${ }^{2}$ ).

Diesen Substanzen werden respective folgende Structurformeln zugeschrieben :

1)<smiles>COC(C)(Br)C1CCC(C=O)CC1</smiles>

2)

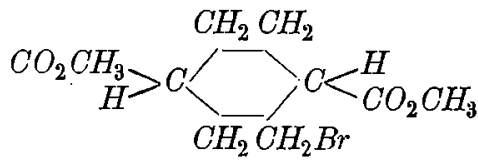

Die. Complexsymbole sind aber respective: 1) 74.6 und 2) 74 .

$$
-6 \text {. } \quad-6
$$

Vergleicht man diese Symbole, so findet man, daß für die beiden Substanzen ein und derselbe rhombische Kern gilt; der Unterschied besteht nur in der Richtung der monoklinen Verschiebung, deren Größe sogar für beide dieselbe ist.

1) Ich sage Winkelisomorphismus, um daraus nicht Schlußfolgerungen über unbestimmtes Zusammenkrystallisieren und andere Eigenschaflen der echt isomorphen Substanzen ziehen zu dürfen.

2) Diese Zeitschr. 17, 477. 
Ich begnüge mich mit diesem Hinweis, ohne weitläufigere theoretische Schlußfolgerungen daraus zu ziehen.

Zum Schluß erlaube ich mir ein paar Worte über die gegenwärtige Sachlage der zur Bestimmung dienenden Tabellen.

Diese Tabellen umfassen elwa 10000 Substanzen und nur etwa 5000 Diagramme, da für isomorphe Substanzen nur ein einziges Diagramm erforderlich ist. Als Grundmaterial dienten die Beschreibungen und Referate, welche in den Bänden 1-48 der Zeitschrift für Krystallographie und auch in den drei Bänden der Chemischen Krystallographie von Groth enthalten sind. Deswegen fehlen in ihnen gerade diejenigen, welche in der allerletzten Zeit in verschiedenen Zeitschriften beschrieben wurden.

Demnächst werden die Tabellen in zwei Teile gesondert, je nachdem die zu prüfende Substanz auf Platinblechen bis zur Rotglut erbitzt einen Rückstand hinterläßt oder dies nicht der Fall ist. $\Lambda$ ußerdem wird in den Tabellen durch ein besonderes Zejchen angemerkt, ob die Substanz (wesentlich) gefärbt ist oder nicht und ob dieselbe leicht schmelzbar ist oder nicht.

Besondere Schwierigkeiten bei der Zusammensetzung der Diagramme entstanden durch außerordentlich oft vorkommende fälschliche (oft sich nur als Druckfehler erweisende) Angaben in den üblichen Colonnen der beobachtèten und berechneten Winkelwerte. Einige davon ließen einen $Z$ weifel bei der Ermittlung der bestimmenden Zahlen. Für viele aber ließen sich die Schwierigkeiten nicht überwinden, und solche Substanzen bedürfen erneuerter krystallographischer Bestimmung. Diese sind natürlich, wie auch diejenigen, für welche sogar der Complex nicht bestimmt werden konnte (falls z. B. eine Zone allein oder nur noch eine einzige Fläche zur Beobachtung kamen), in die Tabellen nicht aufgenommen (ihre Anzabl betrug etwa $700-800$ ).

Seitdem wurde schon eine längere Reihe krystallochemischer Bestimmungen ausgeführt, aber nun als normale Praxis, welche den Bedürfnissen der chemischen Laboratorien entgegenkommt.

Auch ist eine längere Reihe von Beispielen merkwürdiger Verbältnisse zwischen chemischem Bestand und Krystallform aufgezeichnet. Ein vollständigerer Bericht hierüber erscheint jedoch hoffentlich später, wenn das Material in größerem Maße systematisiert sein wird.

Endlich halte ich für meine sehr angenehme Pflicht, meinen herzlichsten Dank allen Herren Collegen auszusprechen, welche zu der Ausführung der vorliegenden Arbeit beigetragen haben. 